\title{
MASTER
}

\section{Overall Requirements for an Advanced Underground Coal Extraction System}

Martin Goldsmith

Milton L. Lavin

October 15,1980

Prepared for

U.S. Department of Energy

Through an agreement with

National Aeronautics and Space Administration

by

Jet Propulsion Laboratory

California Institute of Technology

Pasadena, California 


\section{DISCLAIMER}

This report was prepared as an account of work sponsored by an agency of the United States Government. Neither the United States Government nor any agency Thereof, nor any of their employees, makes any warranty, express or implied, or assumes any legal liability or responsibility for the accuracy, completeness, or usefulness of any information, apparatus, product, or process disclosed, or represents that its use would not infringe privately owned rights. Reference herein to any specific commercial product, process, or service by trade name, trademark, manufacturer, or otherwise does not necessarily constitute or imply its endorsement, recommendation, or favoring by the United States Government or any agency thereof. The views and opinions of authors expressed herein do not necessarily state or reflect those of the United States Government or any agency thereof. 


\section{DISCLAIMER}

Portions of this document may be illegible in electronic image products. Images are produced from the best available original document. 
Prepared by the Jet Propulsion Laboratory, California Institute of Technology, for the U.S. Department of Energy through an agreement with the National Aeronautics and Space Administration.

This report was prepared as an account of work sponsored by the United States Government. Neither the United States nor the United States Department of Energy, nor any of their employees, nor any of their contractors, subcontractors, or their employees, makes any warranty, express or implied, or assumes any legal liability or responsibility for the accuracy, completeness or usefulness of any information, apparatus, product or process disclosed, or represents that its use would not infringe privately owned rights. 
This report presents overall requirements on underground mining systems suitable for coal seams exploitable in the year 2000, with particular relevance to the resources of Central Appalachia. These requirements may be summarized as follows:

(1) Production Cost: demonstrate a return on incremental investment of 1.5 to 2.5 times the value required by a low-risk capital project.

(2) Miner Safety: achieve at least a $50 \%$ reduction in deaths and disabling injuries per million man-hours.

(3) Miner Health: meet the intent of all applicable regulations, with particular attention to coal dust, carcinogens, and mutagens; and with continued emphasis on acceptable levels of noise and vibration, lighting, humidity and temperature, and adequate work space.

(4) Environmental Impact: maintain the value of mined and adjacent lands at the pre-mining value following reclamation; mitigation of off-site impacts should not cost more than the procedures used in contemporary mining.

(5) Coal Conservation: the recovery of coal from the seam being mined should be at least as good as the best available contempory technology operating in comparable conditions.

No significant trade-offs between production cost and other performance indices were found. 
This document describing system level requirements for underground coal mining systems reports results from the initial phase of a program to define, develop, and demonstrate advanced equipment suitable for the resources remaining beyond the year 2000. The program is funded by the office of Mining, United States Department of Energy via an interagency agreement with the National Aeronautics and Space Administration. William B. Schmidt, Director of the Office of Mining, is the project officer for the Department of Energy.

In a very literal sense, this report is the product of a team effort stretching over several years. The ideas which led to the current statement of system requirements began with an earlier draft prepared by Elmer L. Floyd and Paul G. Gordon. Martin Goldsmith was responsible for combining this first effort with more recent results into a logical structure which places clear priorities on the various aspects of system performance, and highlights key factors in each area.

Dr. Goldsmith was assisted in this endeavor by a group of colleagues representing a broad spectrum of disciplines. The acknowledgements which follow are listed in the order in which contributions appear in the document. Jack Harris, Frank Camilli, Charles R. Bickerton, Arnis Mangolds, K. Winslow Farrell, Jr., Patrick J. Sullivan, and Jill Evensizer performed the analysis which described the target resource in quantitative terms. The material in the companion chapter on characterization of mines was prepared by Anthony Lynn, Paul G. Gordon, and Charles R. Bickerton. The description of the baseline technology and projection of its future capabilities was prepared by Charles R. Bickerton, William B. Mabe, Tomas Knurovsky, M. Dean Westerfield, and Gilbert Siegel. Jack Harris, Arnis Mangolds, Anthony Lynn, C. T. Kuo, and Rudolph Kvapil (a consultant to JPL) developed the rock mechanics aspect of the conservation requirement, while Richard P. O'Toole, Amy L. Walton and Lewis J. Perelman examined the contextual issues of intergenerational equity. The section on environmental requirements was prepared by Patrick J. Sullivan, Charles F. Hutchinson, Christopher Stevens, and Elizabeth J. Dutzi. The health and safety requirements were developed by Wayne Zimmerman, with the assistance of Abe Feinberg, Leigh Rosenberg, and two consultants, Myron Goodman, M.D. and Melvin Rosenstein, M.D. Contributors to the production cost requirement included Milton L. Lavin, Katsuaki L. Terasawa, M. Dean Westerfield, Robert L. French, Prof. David R. Whipple (a consultant to JPL), and Energy and Environmental Analysis, Inc. of Arlington, Virginia, who projected target prices for major domestic coal fields. Arlene M. Calvert, Cheryl L. Funk, and Patricia A. South all participated in the lengthy process of transforming drafts into a published report.

Those who wish additional data on the rationale behind the system requirements presented here are directed to the following JPL reports: 


\section{Production Cost and Coal Economics}

C. R. Bickerton, "A Moving Baseline for Evaluation of Advanced Coal Extraction Systems' Cost Performance."

K. L. Terasawa and D. W. Whipple, "Regional Price Targets Appropriate for Advanced Coal Extraction."

Miner Safety and Health:

W. A. Zimmerman, "Safety Evaluation Methodology for Advanced Coal Extraction Systems."

W. A. Zimmerman, "Health Requirements for Advanced Coal Extraction Systems."

Environmental Impact:

P. J. Sullivan, "A Methodology for the Environmental Assessment of Advanced Coal Extraction Systems."

L. J. Dutzi, "The Environmental Assessment of a Contemporary Coal Mining System."

\section{Coal Conservation:}

R. P. O'Toole and A. Walton, "Integenerational Equity and Conservation."

\section{Geology:}

F. A. Camilli and J. Harris, "Geologic Considerations for Underground Coal Mining System Design." 


\section{THIS PAGE}

\section{WAS INTENTIONALLY LEFT BLANK}


TABLE OF CONTENTS

FOREWORD

LIST OF TABLES

viii

LIST OF FIGURES

$\mathbf{x}$

EXECUTIVE SUMMARY

ES-1

1.0 INTKODUCTION

1

2.0 CHARACTERIZATION OF TARGET RESOURCES

2.1 SELECTION OF TARGET REGION

2. 2 GEOLOGY

2.3 CHARACTERIZATION OF MINES IN THE TARGET REGION

3.0 DEFINITION OF THE BASELINE TECHNOLOGIES

3.1 SELECTION OF TECHNOLOGIES 15

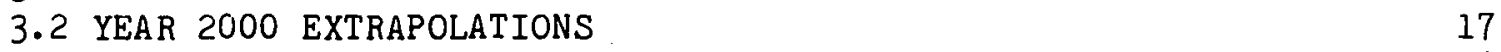

3.3 EXTRAPOLATED ROOM AND PILLAR 18

3.4 EXTRAPOLATED LONGWALL 19

3.5 EXTRAPOLATED SHORTWALL 21

3.6 SUMMARY OF THE MOVING BASELINE $2 \%$

4.0 SYSTEM REQUIREMENTS 27

4. I RESOURCE CONSERVATION $\quad$ 27

4.2 ENVIRONMENTAL IMPACT . . 33

4.3 MINER HEALTH 37

4.4 MINER SAFETY . . . 43

4.5 PRODUCTION COST $\cdot 49$

5.0 SUMMARY . . . 59

APPENDICES

A. THE' RELA'IIONSHIP OF RECOVERY RATIO TO MINING CONDITIONS A-1

B. COAL MINER SURVIVABILITY ? $B-1$

C. DETAILED INFORMATION RELEVANT TO THE SAFETY REQUIREMENT' C-1

D. DETAILED INFORMATION RELEVANT TO THE PRODUCTION COST REQUIREMENTS 


\section{$\underline{\text { Table }}$}

1

2

4

5

6

7

8

9

10

11
Title

$\underline{\text { Page }}$

Coal Production in 1977

6

Eastern Kentucky Coal Resources

6

8

Relationship Between Seam

Thickness and Dip

Resource Tonnage as a Function of

10

Distance from the Outcrop for

Selected Quadrangles.

Overburden Above the Upper-

Most Coal Seam in Eastern

Kentucky

Descripton of the Moving

23

Baseline for Room and Pillar

Longwall and Shortwall

Technology

Estimated Shift Production for

25

the Moving Baseline Technologies

Target Recovery Ratios for Each

Major Mining Technology

32

39

Compared with Expected Deaths

for All U.S. Males, for

Selected Diseases

Summary of Advanced Coal Extraction

42

System Health Requirements

Average Injury Rates in Selected

44

Industries for the Period

1972 through 1978 


\section{LIST OF TABLES}

(Continued)

Table

12

13

14

$A-1$

D. 1-1

D. $2-1$
Title

Distribution of Fatalities, Disabling

Injuries, and Non-Disabling Injuries

in Underground Coal Mining for the

Years 1971 through 1978

Empirical Basis for the ROI Target

Target Prices for Central Appalachia

for the Years 1985 and 2000

Relative Attractiveness of Various

$A-3$

Mining Methods as a Function of

Geological Conditions

0

Minimum Required ROI for an Innovation ( $i$ ) . D-6

as a Function of Payback Ratio ( $\mathrm{m} / \mathrm{m}$ ),

Project Lifetimes ( $\mathrm{n}, \mathrm{n}$ ) and ROI for an

Average Capital Project

Price Influence Coefficients for a

D-10

1.37 ton/yr Room and Pillar Mine

in the Year 2000 


\section{LIST OF FIGURES}

Figure

1

2

3

4

5

6

B. $1-1$

C. $1-1$

C. $1-2$

D- 1
Title

$\underline{\text { Page }}$

Major United States Coal Fields

4

Central Appalachian

5

Coal Region

Percentage of Eastern Kentucky

Coal Resources which are Separated

from Adjacent Coal Seams by a

Speêified Interburden Distance.

Cumulative Underground Coal Production

14

from Eastern Kentucky as a Function

of Mine Size

Underground Coal Mining Methods in

16

the United States

Preferred Technology for Various

Combinations of Mining Conditions

30

B-3

Compared With all U.S. Males, as a

Function of Age

History of Total Injuries per Million

C-5

Man Hours for Underground Coal Mining,

with West Virginia Reported Separately

History of Total Injuries per Million

C-6

Man Hours for Industries Comparable

to Underground Coal Mining

Interpretation of Payback Ratio as a

D-7

12

4

Ratio of Minimum Rates of Return 
The purpose of this report is to outline in broadest terms the performance requirements for an advanced underground coal mining system. Because it is unlikely that the circumstances of all mining regions in the United States will pose the same requirements, a particular target region was selected for examination here. This region, Central Appalachia, was chosen because it possesses adequate coal reserves to support production well into the next century. It is believed that markets for that coal will continue to exist; and mining conditions pose a significant challenge to the system designer.

It was found that most coal beds there are flat-lying, and sufficient resources in seams of greater than 30" thickness exist to support production for many years. Most of the coals lie under less than 1,000 feet of overburden, and many of the coal seams outcrop. Mines range widely in size, but the bulk of production comes from mines in excess of 30,000 tons per year (ranging up to a million tons per year or more). A typical mine size for which the advanced mining system should be targeted is 150,000 tons per year, with a range of from 50,000 tons per year to 250,000 tons per year. (Note that smaller mines are often operated by large firms.) Both caving and non-caving roof control systems are in use, as dictated by the geology.

The performance characteristics of an advanced mining system have been divided into five areas: conservation, environmental protection, miner health, miner safety, and production cost. The requirements, as we have finally stated them, are of two classes. In the first three areas, the requirements are stated as constraints, while in the last two areas, numerical goals have been selected for system performance.

We are unable to justify a numerical goal for the degree of resource recovery, or conservation, to be achieved by an advanced mining system. The constraint, as stated, is that an advanced system should perform as well as existing mining systems in this regard.

The social choice between cost of production and environmental protection has already been made and is implemented through law and regulation. Any advanced mining system must meet existing or future environmental laws. The cost of mitigating off-site impacts must be added to the production cost for the system; an intrinsically non-impacting system will, therefore, have an economic advantage. The second environmental requirement is that any mining system permit the land to be returned to its originally planned use, and the cost of reclamation be added to the cost of producing the coal.

It is found that the primary impact on miners' health arises from dust in the atmosphere of the mine. An advanced mining system should comply with the legal requirement of maintaining dust levels at less than 2 milligrams per cubic meter, either by keeping the dust level throughout the mine under control or by separating the miner from the dust-laden areas. A secondary requirement suggests that the mine atmosphere be kept within reasonable bounds for humidity and temperature in order to minimize respiratory illness. An advanced mining system must also comply with other work environment regulations, such as, noise and illumination. 
Trends in the rate of injuries to coal miners indicate that safety law and regulations are having an effect, and if the trends continue, the overall injury rate to coal miners may well be reduced to about the rates experienced by workers in comparable industries such as construction, petroleum production, etc. However, the rates of serious injuries involving permanent disability or fatality for coal miners are substantially higher than for other industrial groups. Therefore, the performance goal for an advanced mining system is to reduce the rate of those serious injuries by about 50 percent, so that coal mining will enjoy incidence rates similar to the rates experienced by these comparable industries.

It is not sufficient that a new system simply yield a marginally lower production cost when compared to existing practice. In order for a novel mining technology to be accepted by the industry, the rate of return on investment in new equipment must be sufficiently high to compensate for the added risks inherent in the employment of this equipment. Examination of data on the required rates of return in cases of industrial innovation suggests that the new mining system must yield a rate of return $1-1 / 2$ to $2-1 / 2$ times that expected for proven equipment, in order to be accepted by the industry and put into use. This is the key performance factor in setting the production cost requirement for an advanced underground coal mining system. 


\section{SECTION 1}

\section{INTRODUCTION}

The purpose of this report is to delineate the top-level requirements for an advanced coal mining system. The progression of development for any advanced engineering system should be recorded in a series of documents which must begin with the fundamental objectives, or system requirements. The creation of requirements enables the setting of program goals, provides understanding of the constraints, and generally establishes a focus on important issues.

For example, in an aircraft procurement, the system requirements are set forth in terms of total passenger (or payload) complement, maximum route block, landing frequency, airfield characteristics (runway length, altitude, etc.). target operating costs and so forth. This is followed by a system description or conceptual design, which lays out gross dimensions, engine number and thrust, weights, fuel consumption and other matters. The development program is outlined at this stage. The next level is preliminary design where system specifications are set and the project starts to assume the aspect of an engineering development.

In this advanced coal mining system requirement document, we are trying to create a yardstick against which mining systems can be measured. To be considered as an advanced system, a concept would have to exceed in performance, against this yardstick, what existing systems or their logical derivatives might offer. The utility of such a standard is that those who are trying to conceive new mining concepts will clearly understand their goals, and will share a common understanding with those who might wish to sponsor, buy, or utilize such a development.

The standards by which a coal mining system might be judged have been grouped into five attribute areas, which can be separately considered. These areas are conservation of resource, environmental effects, miner health effects, miner safety and production cost. In later sections, each area will be reviewed and quantitative relationships for measuring the worth of a potential advanced mining system will be developed. It will be noted that the mining system is treated like a "black box" in these considerations. The requirements are stated in terms of overall performance; specific technical operating requirements are at a more detailed level, and are not included in this document.

Before a set of mining equipment can be judged, however, its environment must be defined. The environment includes the physical factors of geology and geography, and also market and economic situations, applicable laws, and even the business and social customs of the region. Both mining regions and their mines can vary widely within the United States, and it is unlikely that a universal system, applicable to all mines everywhere, can be developed. Thus we have begun by identifying a target region for examination, and have reviewed the characteristics of the resource there and the nature of the mines. Moreover, an advanced system can only be identified when a 
standard for comparison exists. Therefore, the present state-of-art, and its logical evolution is outlined as a "moving baseline." To be desirable, an "advanced" system must improve on the "moving baseline" in some significant way.

Only then do we consider the five attribute areas to identify those which are the most important to advanced mining system performance. Each attribute area is examined, and both quantitative goals and appropriate evaluation methods are outlined. In most cases, details of methodology are described in other more specialized reports. Advanced system goals and constraints are put in the context of the performance of the moving baseline.

The report concludes by summarizing the requirements for an advanced system, and by suggesting the steps that might be taken next in developing specific concepts or technologies to support the advanced system requirements. 
SECTION 2

CHARACTERIZATION OF TARGET RESOURCES

This section provides information on the operating environment of an advanced underground mining system. Since mining conditions vary greatly from one coal field to another, Central Appalachia, a significant source of underground production, was selected as a target region to illustrate the kinds of factors which define the operating environment. Thus, following a brief discussion of why Central Appalachia was chosen as a target, the geology of the region is described in some detail, with emphasis on considerations which impact seam access, ease of inseam operation, and protection of unrecovered coal. The section is concluded with a characterization of existing mine size as a guide to the scale of new equipment to be developed for this region.

\subsection{SELECTION OF TARGET REGION}

It is known that the various mining regions of the United States (Figure 1) differ in their characteristics. It is as yet unclear how those differences would affect the specification of requirements for an advanced underground coal mining system. For the purposes of concept development, it was decided to choose one target region, and create the system requirements in terms of that geographic area. Subsequently, the same action would be taken for other regions; following that, the regional system requirements could be examined for similarities and differences.

The criteria for selecting a target region were simple. First, there would be little point in using an area whose resource would be of small consequence in the time period of interest (2000 AD and beyond). Second, there should be an expectation of a market for coal from the area. Third, the conditions of mining should present a challenging technical situation. After careful consideration, Central Appalachia was chosen as the target region (Figure 2). This choice was based on several factors. First, a substantial fraction of US coal is produced there, as shown in Table 1. Eastern Kentucky is shown as a sub-region, because much of the detailed analysis used in this report is based on Eastern Kentucky data. As an example, Table 2 shows the coal reserves of Eastern Kentucky. The inferrence of the two tables is that Central Appalachia represents a significant factor of U.S. coal production, and that the reserves in our data area (Eastern Kentucky) will be ample to support mining for an extended time.

A review of the mining situation in Central Appalachia revealed that a variety of geologic conditions exist. Seams are of variable thickness with differing roof and floor structure. The mines vary widely in size, and several mining methods are utilized. Generally, the production cost of coal. seems to be higher than in some other areas, indicating that mining conditions may be more difficult. Lastly, a variety of data exist on the geology, the mines, and mining conditions. The industrial activities of the East coast are predicted to continue to provide a market for Appalachian coal. Thus the 


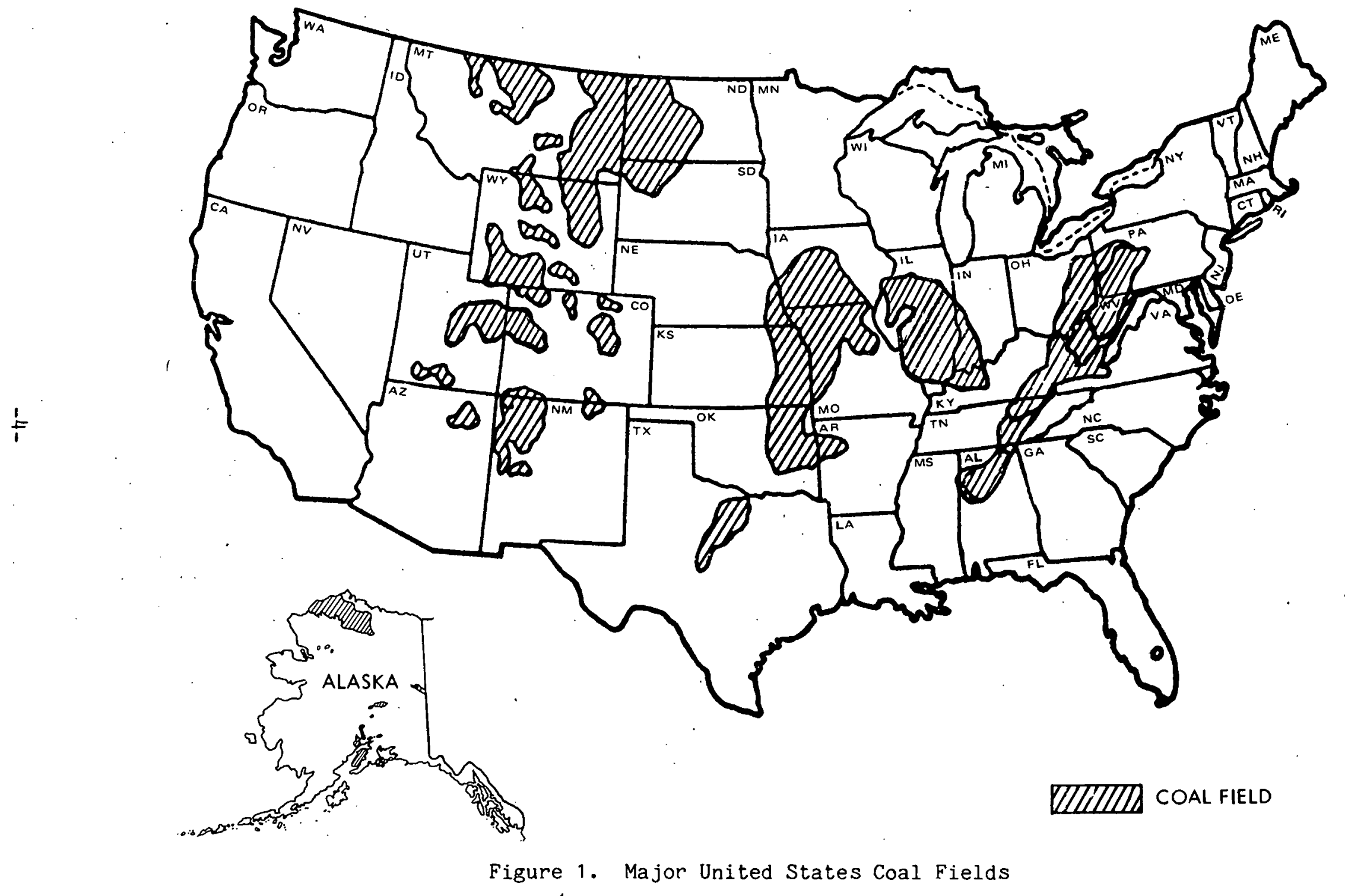




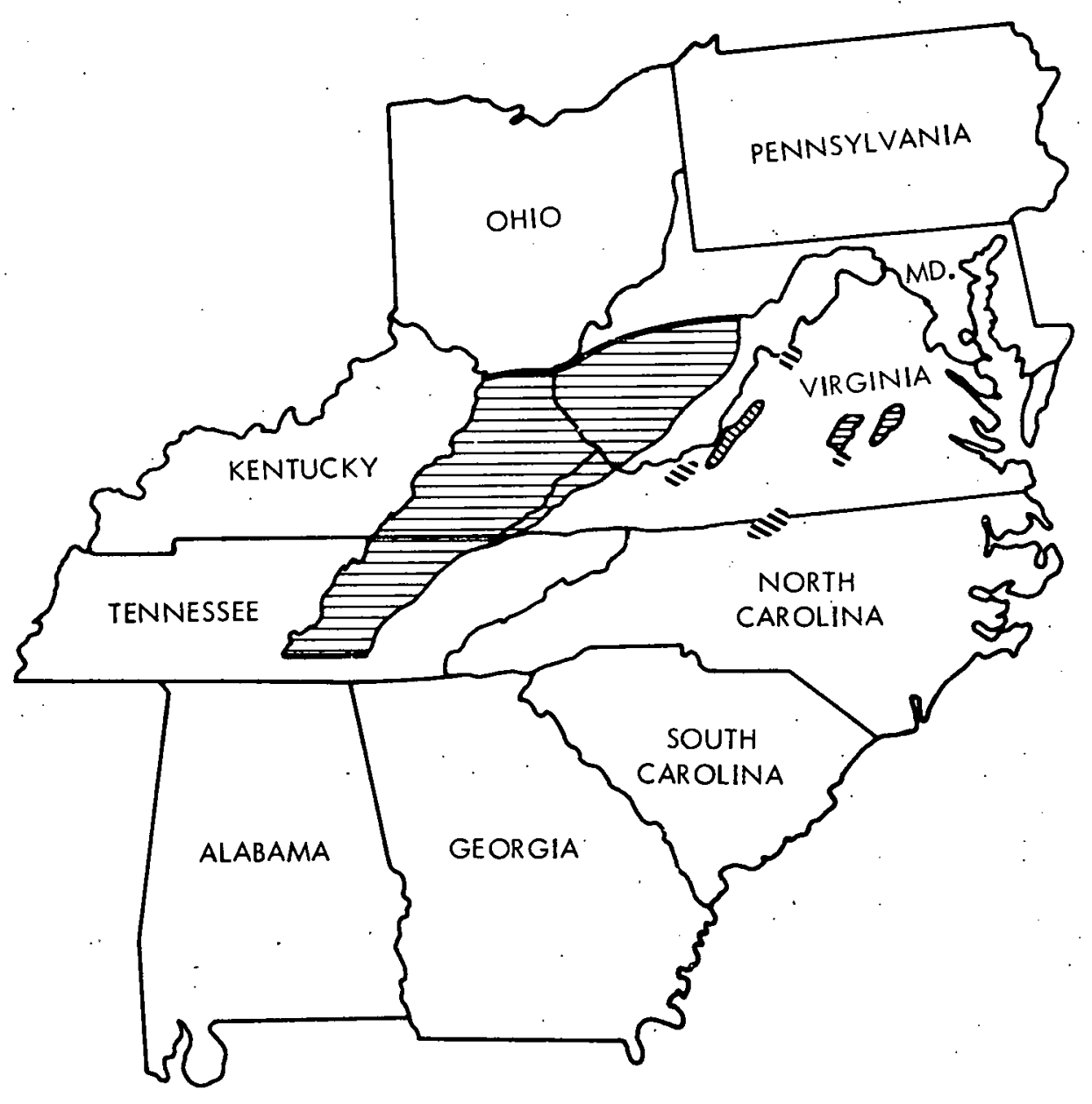

Figure 2. Central Appalachian Coal Region 


\section{TABLE 1}

COAL PRODUCTION IN 1977

(millions of tons)

Source: U.S. Bureau of Mines (1977)

TOTAL U.S. PRODUCTION

TABLE 2

EASTERN KENTUCKY COAL RESOURCES

(millions of tons)

Sources: Averitt (1975)

and Huddle, et al (1963)

$\begin{array}{ll}\text { PROVEN RESOURCES } & \\ \text { IN-PLACE ABANDONED } & 3,100 * \\ \text { THIN SEAMS ( } 28 \text { inches) } & 9,100 \\ \text { THICK SEAMS } & 9,100 \\ \text { SHALLOW COAL } & 4,400 \\ \text { INFERRED RESOURCE } & 5,200 \\ \text { HYPOTHETICAL } & \underline{24,000} \\ \quad \text { TOTAL RESOURCES } & 54,900 \\ \text { *JPL estimate } & \end{array}$


focus on Central Appalachia appears to meet the selection criteria. The specific narrowing to the use of data from Eastern Kentucky cannot be as firmly defended. Limited comparisons made so far indicate that Eastern Kentucky is fairly representative of most of Central Appalachia in terms of mining conditions; further analysis is needed to validate this assumption. However, no claim is made that Kentucky is suitable as a surrogate for all U.S. underground mining conditions. It is very unlikely that this is true; in the future, nationwide data will be reviewed to reveal the differences in regional mining conditions.

\section{$2.2 \quad$ GEOLOGY}

Two wide plateaus comprise the bituminous coal mining province of Eastern Kentucky. These plateaus, which together occupy about 10,000 square miles, are carved into steep hills and sharp ridges by drainage systems that in the north and east flow to the Ohio River, and in the south and west to the Kentucky River system. This mature landscape has shaped mining development significantly by constraining transportation of the coal to market. The hilly terrain exposes most of the coal measures in outcrops. Coal resources buried below drainage are mostly unexplored. The Breathitt Formation, a 1,000 foot thickness of Middle Pennsylvanian sediments hosting most of the region's coal, has only slight structural deformation except along the southern frontier, and so lies nearly flat across the region.

All of Eastern Kentucky's coals are bituminous. The total resource in the region, including the hypothetical, is estimated to be 52 billions tons, entirely excluding resources in the western half of the State. This resource is inventoried in a family of about sixty coal members, none of which appears consistently across the sample territory. The very discontinuous beds are mapped and correlated mainly by their respective positions in the Carboniferous sediments. Only part of the resource is known in detail, and only some smaller part is economical to mine. There are presumably, no other mineral values in the province except building materials. The province has been explored for both oil and gas, and some very modest production is realized. The Breathitt sediments evidence no radioactive mineral content.

Several characteristics of the coal resources lend themselves to quantification which may be useful to the operations planner and systems designer. Most of the analysis which follows drew heavily on Huddle et al $(1963)$.

\subsubsection{Nature of Topographic Slopes}

We have first analyzed the typical slope of the landform surfaces in Eastern Kentucky in order to describe resource accessibility. Analysis of a large number of 7-1/2 minute quadrangle sheets led to the following generalizatons:

(1) In areas dominated by the typical non-resistant facies of the Breathitt formation (the shales, siltstones and some sandstones), the hili and ridge slopes tend to fall at or about 12 degrees. 
(2) Where the more resistant Breathitt members outcrop, the slopes steepen, and tend to fall at or near 26 degrees.

Generally, the softer members, lower relief and more mature landscapes are situated in the northern part of the province where the Ohio River begins to dominate the topography.

\subsubsection{Dip of Coal Seams and Thickness}

The dip (angle of slope) of the resources of Eastern Kentucky was examined in some detail. Of the 220 quadrangle maps that cover the province, 52 were analyzed, giving emphasis to areas where significant deformation is known. The results are shown in Table 3 . It is clear that the overwhelming bulk of the resource is essentially flat-lying, and that ability to mine steeply dipping seams need not be a requirement for the advanced system.

\section{TABLE 3}

RELATIONSHIP BETWEEN SEAM THICKNESS AND DIP (millions of tons)

\begin{tabular}{ccccc}
\hline $\begin{array}{c}\text { SEAM } \\
\text { THICKNESS }\end{array}$ & $0^{\circ}-3^{\circ}$ & $3^{\circ}-10^{\circ}$ & $+11^{\circ}$ & TOTAL \\
\hline $14 "-28 "$ & 9,100 & nil & nil & 9,100 \\
$28 "-42^{\prime \prime}$ & 5,257 & 33 & nil & 5,290 \\
$42^{\prime \prime}-120 "$ & 3,871 & -5 & nil & 3,876 \\
TOTAL: & 18,228 & 38 & nil & 18,266 \\
\hline
\end{tabular}

\subsubsection{Relation of Resource to Outcrop}

In the sample province of Eastern Kentucky, where the relatively flat coal bodies of the Breathitt Formation outcrop extensively, an analysis was made of the relationship of topography and outcrop of the multiple coal seams, to provide the designer with additional information on seam access. Mapped seams were measured by planimeter, and a typical thickness hypothesized from the literature. Contours were plotted inwards 200 feet from the outcrop, then 500 feet, and 1,000 feet. Thus, for each seam, the resources were categorized to establish amounts available to surface mining (within 200 feet of the outcrop); and that interior coal, deeper than 1,000 feet from outcrop, which probably must be extracted by some underground method. 
The present effort measured only two quadrangles: the Grayson in District 1, and the Broadbottom in District 4. The results are displayed in Table 4. Note that about 60 percent of the coals in the Grayson Quadrangle lie within 200 feet of the outcrop, whereas only 20 percent of the resource in the Broadbottom Quadrangle are similarly situated. Examination of the landforms and their relationship to where each quadrangle lies in the drainage network, reveals the principal reason for the observed differences in seam access: The Grayson Quadrangle, characterized by low, narrow ridges, is located near the floodplain of the Ohio River in relatively mature topography. In contrast, the Broadbottom Quadrangle, exhibiting higher relief and broader ridges, is situated in the headwaters of its drainage network, near the Allegheny uplift. Thus, these two quadrangles probably portray the extremes of the range of topographic conditions which determine what fraction of the coals lie within a certain distance of the outcrop.

\section{¿.c.4 Buried Resources}

- Buried coal bodies in Eastern Kentucky have not been fully described in the public record. This is partly because the Breathitt Formation, which hosts practically all of Eastern Kentucky's exploited coal horizons, is almost entirely exposed to its basement by the drainage system; in other words, there has been no impetus to map buried resources.

\subsubsection{Relationship of Coal Resources and Interburden}

For advanced extraction system conceptualization and design, we have sought to identify, analyze and characterize the sedimentary rock interburdens between coal members. T'wo avenues of inquiry were followed: one, to quantify the interburden dimensions; the other, to characterize the nature of the interburden materials. The first was completed and its conclusions are indicated in Figure 3. We found that no meaningful generalization was possible about the composition of the interburden material.

The results presented in Figure 3 indicate that 65 percent of Eastern Kentucky's coals lie in bodies separated from the next superimposed body by a sedimentary rock thickness of over 60 feet. The balance is more narrowly separated, and there mining of one seam may impede or prevent access to neighboring seams. This has consequences for the conservation of resource.

\subsubsection{Overburden Above the Uppermost Coal Member}

The mature, rolling topography of the sample province, superimposed upon an irregularly spaced series of almost flat coal horizons, establishes overburden in a haphazard pattern. An analysis, paralleling the interburden study, indicated the variation in overburden thickness across the province presented in Table 5. 
TABLE 4

RESOURCE TONNAGE AS A FUNCTION OF DISTANCE

FROM THE OUTCROP FOR SELECTED QUADRANGLES

(millions of tons)

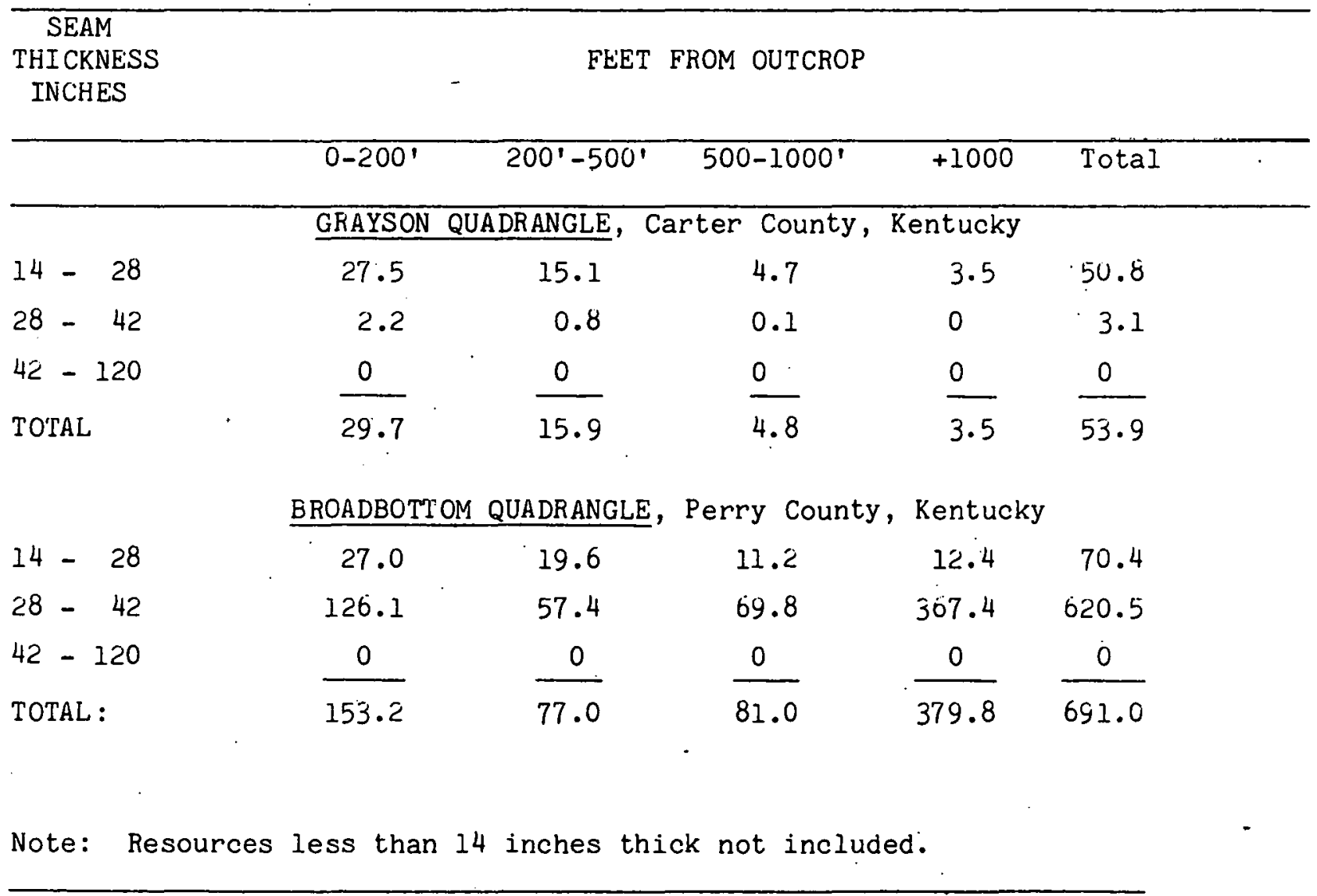


TABLE 5

OVERBURDEN ABOVE THE UPPERMOST

COAL SEAM IN EASTERN KENTUCKY

\section{Vertical Feet}

\begin{tabular}{crrrr} 
District* & Min & Seam** & $\underline{\text { Max }}$ & Seam** \\
\hline 1 & 85 & $\# 77$ & 453 & $\# 67$ \\
2 & 10 & 104 & 320 & 96 \\
3 & 20 & 111 & 263 & 100 \\
4 & 101 & 91 & 433 & 96 \\
5 & 190 & 111 & 585 & 212 \\
6 & 398 & 135 & 443 & 104
\end{tabular}

*Districts after Huddle (1963).

**Seam numbers after Bureau of Mines Information Circular No. \#8655

\subsection{CHARACTERIZATION OF MINES}

Data concerning mine size and ownership have been analyzed for Central Appalachia, with emphasis on Eastern Kentucky and West Virginia. According to data published by the National Coal Association (1979), West Virginia, Virginia, Tennessee and Eastern Kentucky together have 75 percent of the underground coal mines in the United States. These mines employ 61 percent of the nation's underground coal miners and produce 53 percent of the deep mined coal. In general the mines are small and scattered.

West Virginia produces 55 percent of the area's underground coal. In 1978, only one West Virginia operator, Consolidation Coal Co., had mines with individual production over 1,000,000 tons per year. This operator is atypical. Recent data reported by the West Virginia Department of Mines (1978) indicates that West Virginia underground coal production can be divided as follows:

(1) Consolidation Coal Co.'s 10 largest mines produce 19.7\%.

(2) The 430 mines belonging to operators with a total annual production of less than 100,000 tons produce $14.4 \%$. 


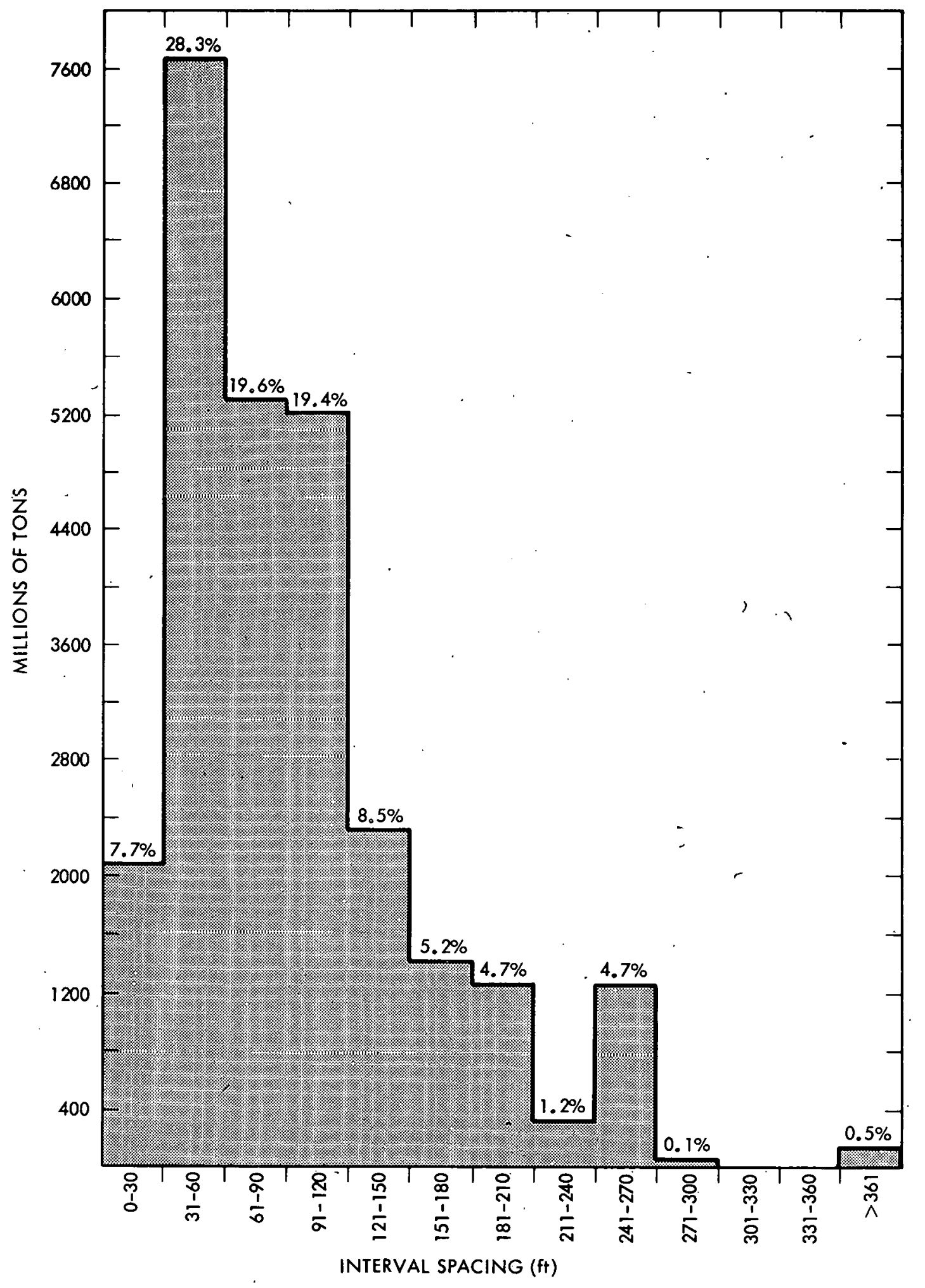

Figure 3. Percentage of Eastern Kentucky Coal Resources which are Separated from Adjacent Coal Seams by a Specified Interburden Distance 
(3) The remaining $65.9 \%$ comes from 346 mines.

Analysis of the data in this last category produces the following characteristics of the "typical" West Virginia mine:

(1) Mine size - 125,000 tons/year.

(2) Employment - 85 workers.

(3) Two sections working two shifts.

(4) 160 average annual working days in 1978.*

Although mining operations are scattered, ownership and control are not. A great many operators have more than one mine. All of the largest operators have several mines. Over 75 percent of West Virginia production is ultimately owned or controlled by large oil or steel companies, electric utilities or industrial conglomerates. Thus, capital availability for most mines will reflect national conditions. The "typical" mine operator, among the larger West Virginia producers:

(1) Works 4.3 mines simultaneously,

(2) has total annual production - 540,000 tons/year,

(3) employs 365 people, and

(4) is owned or controlled by a larger entity.

These results are quite consistent with the data on mine size reported by the Kentucky Department of Mines and Minerals (1978). Figure 4 presents the cumulative production for all Kentucky mines, ordered by size. Excluding the smallest 965 mines which together aggregate 25 percent of East Kentucky's production, the remaining 263 mines produce 75 percent of the region's deep mined coal and have an average output of 123,000 tons/year. The median sized mine (50 percent of total from larger mines - 50 percent from smaller) for East Kentucky produces between 100,000 and 125,000 tons/year. Aggregation of the West Virginia and East Kentucky data indicates that the median sized mine produces 175,000 tons/year.

While the very small mines might benefit from some advanced technology, their cumulative production is too low to warrant considering them in formulating system requirements. On the other hand, the few very large mines present special cases. Our judgment is that for Central Appalachia the advanced mining systems requirement should be focused on mines ranging from $50,000 *$ * to 250,000 tons/year production, centering about the 150,000 ton/year level.

\footnotetext{
1978 was a year marked by significant work stoppages.

50,000 tpy is a typical output for a single section mine operating with a single shift.
} 


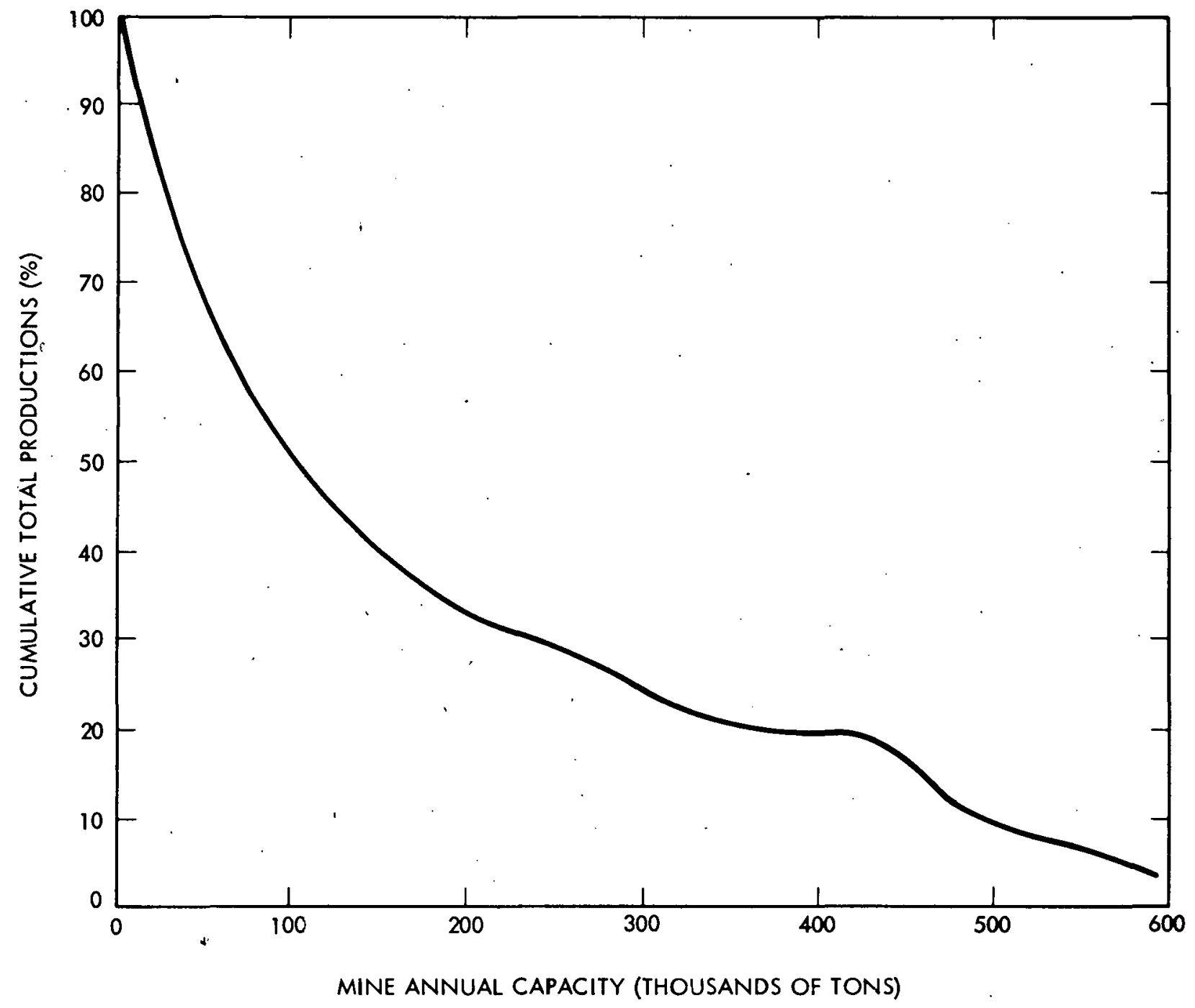

Figure 4. Cumulative Underground Coal Production from Eastern Kentucky as a Function of Mine Size 


\title{
SECTION 3
}

\author{
DEFINITION OF THE BASELINE TECHNOLOGIES
}

In order to determine whether a concept is actually an advanced system, its performance must be compared to the other underground mining systems which will exist at the time the new concept has matured to a commercially acceptable form. In other words, the concept must be compared to contemporary mining systems that have evolved over time. Since the year 2000 has been selected as a nominal target year, present systems will be projected to their conjectural states in the year 2000. This is the moving baseline.

First, the systems to be studied will be selected and extrapolated to the year 2000. Then, the performance parameters needed to determine system productivity will be identified and quantified. After productivity is established, the mining systems can be partnered with appropriate mine plans so that discounted cash flow analyses can be performed in order to arrive at measures of economic performance.

\subsection{SELECTION OF TECHNOLOGIES}

Three of the technologies currently used by the underground coal mining industry were considered appropriate for this study. They are room and pillar with a continuous miner, longwall, and shortwall. Continuous room and pillar was selected because it accounts for over b0 percent of U.S. underground production today, and as Figure 5 shows, has made a rapid entry into the industry over the past years. Although there are many possible system configurations, examination of equipment available for continuous room and pillar by Frantz et al (1977) indicated that the most common scheme uses a rotary-drum continuous miner partnered with shuttle car haulage and supported by a dual-boom roof bolting machine. Therefore, this system configuration will be used as representative of the contemporary, 1980, case.

Longwall, which is applicable to mines at the upper end of the size range, was selected for several reasons. First, as shown in Figure 5, longwall has a consistent rate of entry into the market. Additionally, according to Kuti (1979) and Business Week (19\%8), longwall may account for a considerable portion ( 12 to $25 \%$ ) of underground production by 1985 . If these projections are extended at the same rate to the year 2000 , longwall could contribute from 26 to $61 \%$ of underground production. Noreover, longwall mining systems account for the majority of underground coal production in many European countries. All of these factors suggest that longwall systems hold great promise for the U.S. coal industry. Kuti (1979) reports that the most commonly used longwall configuration in the U.S. incorporates a double-drum shearer with an armored face conveyor and chock-type hydraulic roof supports. This system is chosen to represent the contemporary, 1980, case.

For longwall panel development, the system selected contains a rotary-drum continuous miner and a mobile bridge carrier ( $M B C$ ) haulage unit. 


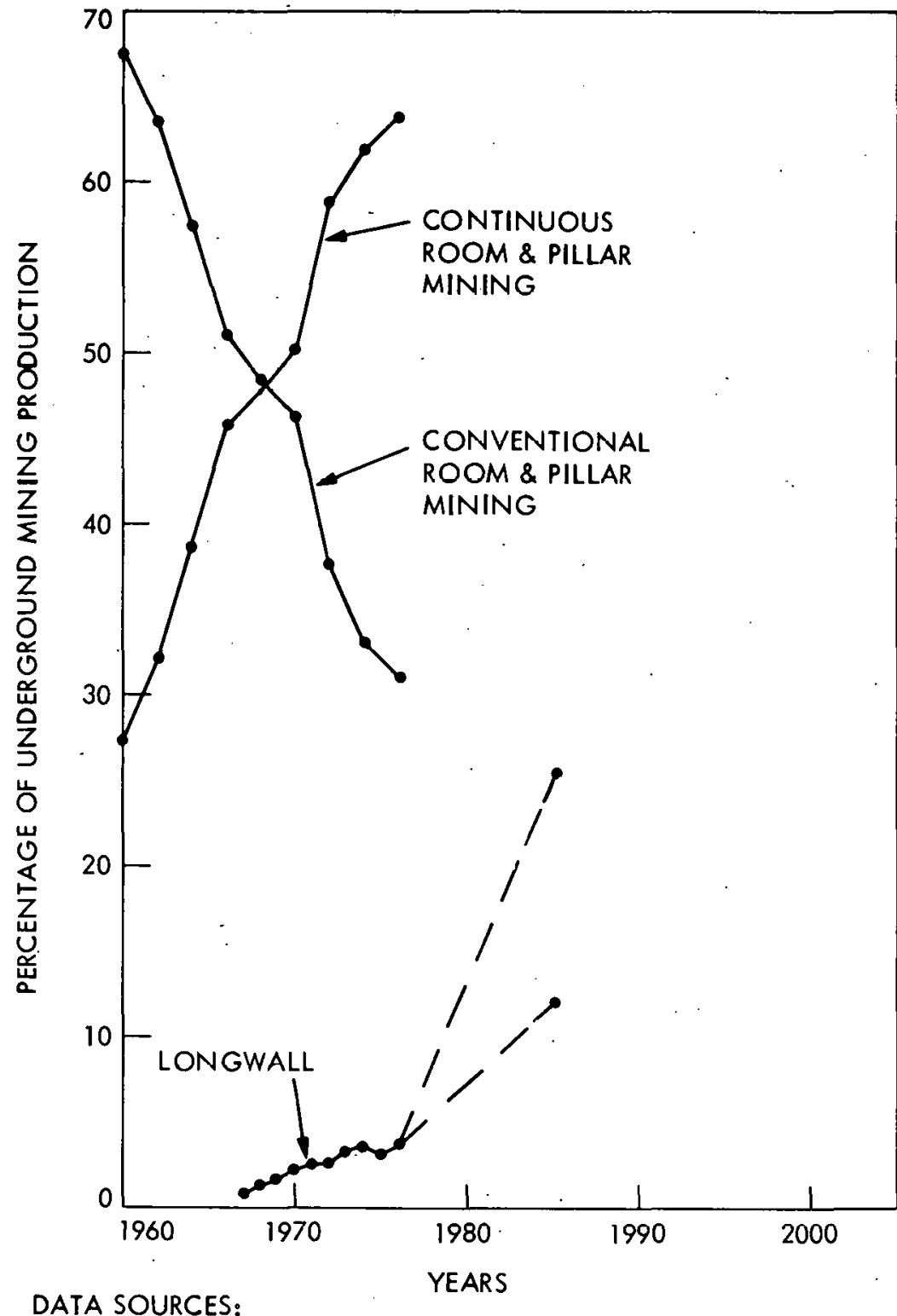

1960 - 1976: NATIONAL COAL ASSOCIATION, COAL FACTS, 1978 - 1979 HIGH LONGWALL PROJECTION: BUSINESS WEEK (1978) LOW LONG WALL PROJECTION: KUTI (1979)

Figure 5. Underground Coal Mining Methods in the United States 
The system is basically room and pillar technology applied to panel development. The MBC unit was selected because it provides better haulage service to the continuous miner than shuttle cars, thus affording a higher potential productivity. At this time, the MBC unit is second only to the shuttle car in utilization and is increasing in popularity. Thus, it was thought appropriate to team this system with the longwall.

Shortwall technology, while presently producing only a small fraction of the U.S. total production, is relatively new. Shortwall has several advantages over longwall and continuous room and pillar in proper circumstances. Shortwall is a caving system and functions well at shallow depths under massive roof strata; Stefanko (1977) notes that it is more flexible than longwall for skirting undesirable geological and man-made situations. Shortwall also is felt to have better health and safety characteristics than room and pillar, and can offer production cost advantages as well. Pollard (1975) reports that the European and Australian mining establishments have considerable interest in the future application of shortwall because of its flexibility. The shortwall systems that have been tried in the U.S. (there have been about 1.1 of them) normally used the panel development equipment in conjunction with chock-type roof supports for production. We have elected to use the same development system for shortwall and longwall as a basis for projections. Thus, both development and production systems for shortwall will contain a rotary-drum continuous miner and a MBC haulage unit.

Conventional room and pillar technology was not selected for study because it is felt that the technology has reached its maturity, and will not experience significant changes in the future. Evidence of the drastic decline in conventional production is shown in Figure 5. This prolonged trend suggests that it will not be an important alternative in the future.

\subsection{YEAR 2000 EXTRAPOLATIONS}

The projection of the contemporary systems to the year 2000 will emphasize three mining functions: cutting, haulage, and roof support. While other mining functions have impact on system productivity, it was felt that the above-mentioned functions were most important. For all three technologies, it is anticipated that improvements will be made in dust control, gas control, equipment safety and equipment reliability. Projections of the progress to be expected in each of the major technologies was based in part on a survey of current research and development activities reported by Gordon (1980), a member of the Jet Propulsion Laboratory project staff. Continuing review of published reports and journal articles, and contact with the responsible government agencies have provided supporting information.

In addition to determining the focus of research and development activities in the industry, we have identified significant production constraints for each of the major mining methods. For room and pillar, two major constraints were identified, the frequency of continuous miner place-change and the intermittency of shuttle-car haulage service. The key constraints on the longwall's materials handling capability are the capacity of the armored face conveyor and its utilization, and the advance rate of the 
supports. An analysis of the contemporary, 1980 shortwall system identified the cutting width of the continuous miner and the mode of support advance as the major production constraints. The following paragraphs provide more detail about the constraints and the system modifications that might be expected to improve the situation in the future.

\section{3:3 EXTRAPOLATED ROOM AND PILLAR}

A statutory provision of the Federal Coal Mine Health and Safety Act of 1969 prohibits movement of personnel beyond the last permanent support unless adequate temporary support is provided. To comply with this provision, many mine operators elected to shorten continuous miner advance distances so that the locally positioned operator remains under permanent support. The advance distance is generally 18 to 22 feet, depending on the machine design. This leads to the first production constraint mentioned for room and pillar, but also effects panel development in all systems. Several equipment manufacturers have developed devices for remote control operation, and also offer locally controlled miner-bolter machines that permit permanent support placement in conjunction with entry advancement. Both developments al.low continuous miner advancement to approach the pre-1969 situation of breakthrough-to-breakthrough length lifts (60 to 100 feet). However, each development has its drawbacks. Remote-control operations are limited by operator vision, the position of haulage operators with respect to the last permanent support, the stability of the roof, and other factors. Most miner-bolter machines experience roof-bolting delays that erode the potential time savings.

Stefanko (1975), Frantz (1975 and 1977), and National Mine Service (1979) have described various aspects of the Department of Energy's program to develop an automated remote-controlled continuous mining system. The aim of the program is to develop a miner-bolter machine that can function without the aid of on-board operators. To date, the program has not demonstrated a fully automated system.

Harold (1979) describes another approach which has increased production by 27 percent in initial tests. This involves hydraulically activated roof support beams that are advanced with another set of hydraulic cylinders. This roof support system allows a locally-controlled continuous miner to advance further by providing adequate temporary support. The support unit is only in the initial development phase, but has great promise because it provides a very simple, straightforward solution to the roof support problem, and it can continue to be used with present equipment as it evolves.

The second room and pillar constraint, the intermittent service provided by shuttle cars, may be eliminated by use of a continuous haulage system, such as the mobile bridge carrier (MBC). While there are several reasons why industry uses shuttle cars more extensively than MBC units, Frantz, et al (1977) note that the major reasons concern surge capacity, maintainability, and ease of operation. Positive steps are being taken to make improvements in these three areas. Some chain-conveyor MBC units have a surge bin option. Arthur D. Little (1977) conducted a conceptual study of an automated remote-controlled continuous room and pillar. mining system with a 
surge feeder unit between the continuous miner and MBC unit. This conceptual system is part of a long-term development program in the Department of Energy. Mayercheck (1979) reports that the Department of Energy is also developing an "auto-track" MBC unit in order to improve the tracking and guidance of an MBC deployed behind a continuous miner. With a feedback control system, the MBC unit will straddle and follow an induction cable that is laid on the mine bottom by the lead segment of the unit which is under local, manual control. This addition will ease guidance and control problems.

As the previous discussion indicates, there are several future system options that directly address current room and pillar constraints. For this moving baseline, we have selected a standard rotary-drum continuous miner, with a ten-foot wide cutter head, partnered with an auto-track MBC unit, hydraulic temporary roof support units, and dual-boom roof bolters. This system is seen as an obvious evolution of existing equipment that does not require a great deal of sophisticated hardware and at the same time minimizes functional interactions. This system will also be used for the year 2000 longwall and shortwall development cases.

\subsection{EXTRAPOLATED LONGWALL}

Turning to longwall systems, the major constraints are the capacity of armored face conveyors, the under-utilization of face conveyor capacity, and the advance rate of roof support units. It is not clear that any major advances in face conveyor capacity in the near future will take place. Conveyor capacity is governed by the cross-sectional area of the conveyor pan and the speed of the conveyor chain. The cross-sectional area is presently constrained by the design of the roof supports and the shearer, and conveyor flexibility requirements. Therefore, an increased cross-sectional area of the conveyor will require an extensive system redesign. How this redesign might be accomplished is not clear.

Present chain speeds are limited in order to minimize the wear rate of chain links. While several attempts have been made to develop lubrication systems, Dumbrack (1979) indicates that none seem acceptable. The ultimate solution may be more abrasive-resistant materials for the links, or friction-reducing liners for the conveyor pans. While it is certain that manufacturers and researchers are investigating this avenue, no positive results have been published. Thus, it is evident that present conveyor capacities may be the major limiting factor for longwall production. We have adopted that viewpoint in constructing the moving baseline. Schroeder, et al (1978) and Rybak (1979) reached this same conclusion in their studies of future systems.

On the other hand, conveyor capacity is presently under utilized because operational cycles for shearers have a considerable amount of nonproductive time. Bickerton (1980), illustrated this point in his analysis of the half-face method currently used most commonly in the U.S. The nonproductive segments of the shearer cycle for the two cases examined ranged from 30 to 47 percent of the total cycle time. To improve conveyor utilization, two shearers (or more) could be placed on the face. The National Coal Board (1976) reports that this practice is quite common in the United 
Kingdom. Each shearer would be assigned to a particular segment of the face. With the use of an interactive control system, each shearer would cut its segment of the face such that the conveyor is not overloaded and collision of the shearers is avoided. Analysis of this configuration, by Bickerton (1980), showed a 33 percent decrease in the cycle time while obtaining the same production per cycle as the one-shearer scheme.

While the dual-shearer face approach increases shift production by better utilizing conveyor capacity, other approaches found in the literature address the instantaneous production rate of shearers, and health and safety impacts on longwall workers. Gross (1979) and Schroeder, et al (1978) describe efforts to increase the production rate by cutting a wider web. In one of these studies maximum shearer production rate was constrained by conveyor capacity.

The present approach to automated longwall promises to improve miner health and safety by removing personnel from critical areas, and should, in addition, lay the groundwork for a future dual-shearer configuration. The development program underway at the George $C$. Marshall Space Flight Center (1977) has identified three basic systems required for automated, remote-controlled longwall mining: a vertical control system for the shearer, a face advancement system, and a master control system. Efforts are underway to develop these systems for application to existing longwall configurations. Such developments will clearly support the application of automation and remote control to the dual-shearer configuration. Summers (1979) has observed that British attempts at automated longwall were partially successful, but encountered labor/management problems. Their experiences, nevertheless, will benefit American developments. Therefore, our prediction of automated longwall options by the year 2000 does not seem unreasonable.

A third longwall production constraint is the slow advance rate of the roof support units. Cominec (1976) reports that the "state-of-the-art" cycle time for a support is about 10 seconds. This value transforms into a. support advance rate along. the face of 30 feet per minute because supports are normally placed on five foot centers. Therefore, the shearer travel rate along the face should be limited to 30 feet per minute.

According to 01sen (1977), under ideal circumstances, most roof support systems can be advanced along the face at a rate of 50 feet per minute. However, several factors limit support advance rates: (1) movement of the face conveyor; (2) the loss of fluid pressure and fluid flow; (3) lowering the support from the roof in preparation for advancement; and (4) raising the support to the roof after advancement. The first factor led to the development of the "one web-back" method of face advance. This method eliminates face advance delays caused by conveyor movement needs, improves roof control, and increases the available travel space between the conveyor and supports. Consequently, many American operators are adopting this technique. The second factor is related to the inadequacy of hydraulic power pack capacity and the buildup of back pressure in the return line. Olsen (1977) notes that these problems can be alleviated by increasing the capacity of the hydraulic system. 
The last two factors result from the design of longwall powered supports. In order to improve upon the situation, the basic support design must be modified. Casanova (1979) describes an attempt by the French Collieries Research Institute to develop a crawler-mounted hydraulic roof support. This design permits advancement under load, thereby eliminating the vertical roof-beam movement required with conventional longwall support designs. It is not yet known whether the crawler sliding support is superior to the conventional support, but Casanova reports that there are several prototypes in the field.

The following system components are proposed for the extrapolated year 2000 longwall system:

(1) Two double-ended ranging drum shearers having vertical control systems.

(2) Powered roof support units.

(3) An armored face conveyor (AFC) with a peak capacity of 1,500 tons per hour.

(4) A stageloader that can adequately handle peak loads from the AFC.

(5) A face advancement control system for the supports and AFC.

(6) A master control system that effectively coordinates all face activities.

\subsection{EXTRAPOLATED SHORTWALL}

As previously mentioned, the cutting width of continuous miners presently used in shortwall systems is normally 10 feet. Because of this width, the roof supports must function such that situations are created that constrict production performance. These situations involve the rate of face advance and strata control.

During a face advance cycle, each support unit is moved forward twice, about five feet each time. The first advance occurs as the continuous miner cuts along the face, and results in little, if any, production interference. The second advance does not start until the continuous miner finishes cutting and starts tramming out of the face area. The resulting production interference is quite significant, accounting for 21 to $28 \%$ of the cycle time, according to Bickerton (1980).

Katen (1979) and Moyercheck (1979) note that several shortwall operations have failed or have experienced many production delays because of poor roof conditions. While these basic conditions are a result of natural processes, the unsupported roof area and quality of roof support that exists at the face accentuates the problem. While the continuous miner is cutting, the unsupported area is typically in the range of 400 square feet ( 40 feet by 10 feet). After the initial support advance, a span about five feet wide along the entire face length ( 180 to 200 feet) is poorly stabilized by the forepole devices of the supports. This situation, along with the unsupported 
roof span, promotes rock falls along the face. These not only delay production during their clean-up, but the resulting cavities also reduce support effectiveness and accentuate the problem.

Because these problems exist at present cut widths, Pollard (1975) and Stefanko (1977) have suggested narrower cuts. The extrapolated year 2000 shortwall system incorporates this suggestion. A review of current continuous miner specifications identified 7.75 feet as the narrowest miner chassis width with a cutter head minimum of 8.5 feet. Discussions with equipment designers, including Freed (1979) suggested the possibility of a narrower body and cutter head. Therefore, a seven-foot wide cutter head was elected for the extrapolated case. To complement this narrow continuous miner, Kiskis (1979) designed a support to achieve a seven-foot advance. It is also assumed that a continuous haulage system can be designed to accommodate the space limitations. An analysis of this extrapolated system revealed shift production increases ranging from 17 to $35 \%$, depending upon the mining conditions.

\subsection{SUMMARY OF THE MOVING BASELINE}

The moving baseline is summarized in Table 6 , where the features of room and pillar, longwall, and shortwall development and production equipment are listed. In Table 7 we present estimates of the ranges of production rates expected from the moving baseline systems. The basis for these estimates is reported in Bickerton (1980). 
DESCRIPTION OF THE MOVING BASELINE FOR

ROOM AND PILLAR, LONGWALL, AND SHORTWALL TECHNOLOGY

Room-and-Pillar

1980

- Continuous Miner

- 20-Foot Lift Length

- Shuttle Car Haulage

- Roof Bolter

- Partial Extraction Operation
- 5-Entry Mine Plan

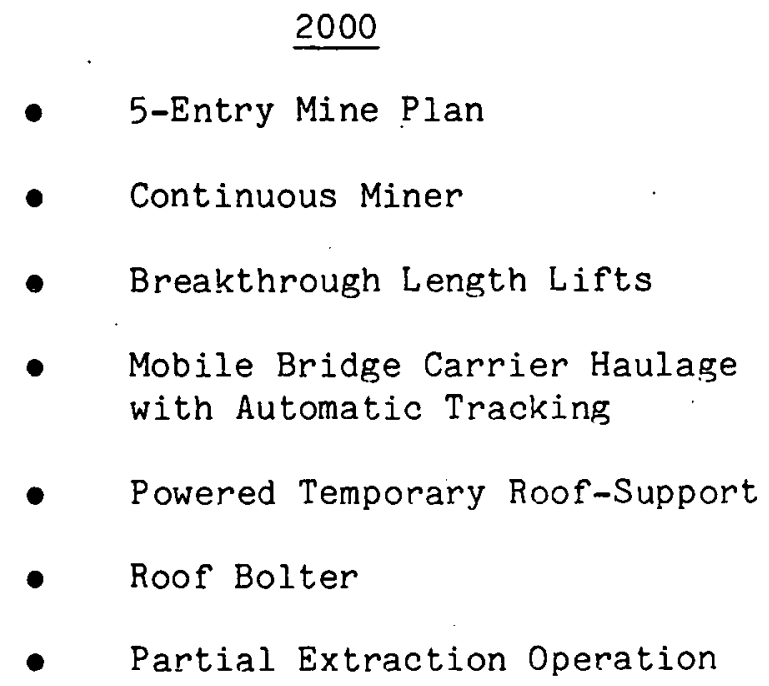

\section{Longwall and Shortwäll Development}

1980

- 3-Entry Mine Plan

- 3-Entry Mine Plan

- Continuous Miner

- Continuous Miner

- 20 to 40 Foot Lift Lengths

- Breakthrough Length Lifts (80 Feet)

- Mobile Bridge Carrier Haulage

- Mobile Bridge Carrier Haulage with Automatic Tracking

- Roof Bolter
Powered Temporary-RoofSupport System

- Roof Bolter 
TABLE 6

MOVING BASELINE MINING SYSTEMS

(Continued)

Longwall Production

1980

- 500-Foot Face

2000

- 500-Foot Face

- Half-Face Operation

- Half-Face Operation

- One Double-Ended

Ranging Shearer (DERS)

- Two Double-Ended

Ranging Shearers (DERS)

- Armoured Face Conveyor (AFC)

- Armoured Face Conveyor (AFC)

- Powered Supports

- Powered Supports

- Automatic Control of DERS, $A F C$, and Supports

Shortwall Production

1980

$\underline{2000}$

- 180-Foot Face

- $\quad 180-$ Foot Face

- Continuous Miner

10-Foot Head

- Continuous Miner

7-Foot Head

- Mobile Bridge Carrier

Haulage

- Continuous Haulage

- Powered Supports

Powered Supports, Permitting

One-Step Advance 
ESTIMATED SHIFT PRODUCTION FOR THE

MOVING BASELINE TECHNOLOGIES*

\begin{tabular}{lcc} 
& \multicolumn{2}{c}{ RAW TONS PER MACHINE - SHIFT } \\
\cline { 2 - 3 } & $\frac{1980 \text { Systems }}{\text { Continuous Room-and-Pillar** }}$ & $\frac{2000 \text { Systems }}{290-680}$ \\
$\begin{array}{l}\text { Longwall and Shortwall Panel } \\
\text { Development* }\end{array}$ & $450-1330$ & $560-1590$ \\
$\begin{array}{l}\text { Longwall Panel Production } \\
\text { Shortwall Panel Production }\end{array}$ & $830-1770$ & $530-1390$ \\
\hline
\end{tabular}

Those numbers are estimates of the performance of "best available" technology operating in from average to ideal conditions by an experienced workforce.

* Room and Pillar differs from Longwall and Shortwall Panel Development in 1980 because of the influences of tons per panel and panel move time. The year 2000 cases differ because of mine plan differences. 
THIS PAGE

\section{WAS INTENTIONALLY \\ LEFT BLANK}


SECTION 4

SYSTEM REQUIREMENTS

Consideration of the concerns that have been expressed by miners, operators, government personnel and the public suggest that five areas should be separately identified in the system requirements. These are:

(1) Resource Conservation

(2) Environmental Protection

(3) Miner Health

(4) Miner Safety

(5) Production Cost

Each subject is covered in this section of the report, with the objective of developing specific goals or targets for an advanced underground coal mining system. These requirements fall into two categories: the first type are stated in terms of a constraint; the second are stated as numerical goals. It is proper to point out that there is seldom a rigorous basis for the setting of system requirements; in most cases there are many debatable issues. The authors of these requirements have exercised judgment, and have subjected these judgments to the scrutiny of others in order to test their reasonableness. It is recognized that system requirements are subject to revision as development progresses and issues are clarified.

\subsection{RESOURCE CONSERVATION}

4.1.2 Introduction

Underground coal mining necessarily disrupts the ground, and affects the conservation of the resource in two ways: (1) the amount of resource (sometimes rubblized) that might be left in place because of inefficiency, technological limitation, or economic penalty; and (2) the disturbance or damage caused to any nearby coal body. No underground coal mining method or system has demonstrated, or promised, the ability to remove all of the mineral, either because of safety or environmental constraints. Even the most successful and productive methods have limits imposed by their basic design and by their need to assure safety and productivity. Extraction efficiency (resource recovery) is greatly affected by the technique used to create and maintain the mining work space.

\subsubsection{Mining}

Some mining methods seek an optimum extraction ratio while maintaining full support of overhead rock and earth to delay caving or 
collapse (e.g. room and pillar with no pillar robbing); other methods intentionally cave the cover rock in a controlled manner to relieve the otherwise unmanageable accumulation of rock stress (e.g. longwall). Still other. methods combine the two techniques of ground control (e.g. room and pillar with pillar robbing). The choice of a particular technique depends upon many conditions and the impact upon production cost.

Limits are imposed upon the extraction efficiency of any system by the necessity for support of openings used for access, ventilation and transportation, all of which occupy significant area. Other support limits may be imposed where the protection of superimposed strata or the ground surface is necessary. In some states, the utilization of efficient caving systems which cause surface subsidence is often precluded by law or regulation.

Other factors can cause coal to be left in the ground unrecovered. For example, contemporary mining machinery is bulky so that it cannot be deployed in thin coal beds; no support method can control unconsolidated or shattered roof rock; and non-coal material (partings) within the seam may reduce or eliminate the value of the product. The motivation for seeking an increased recovery fraction is apparent; to waste a valuable energy source by rendering it inaccessible seems inappropriate. However, there are sharply differing viewpoints on this issue. In a separate paper 0'Toole (1980) argues that increased recovery may not be worthwhile, even to future generations, if the cost of recovery could be better spent in other human endeavors. These arguments are flavored by the fact that the U.S. has several hundred years supply of economically recoverable coal, at present consumption rates. There is also the implicit expectation that in such a time frame, coal will be replaced by alternative energy sources. Perelman (1980), a proponent of the opposing viewpoint argues that should the use of coal increase at even a modest exponential rate, our coal supplies would look more valuable and conservation would appear much more attractive. Clearly, no resolution of this fundamental issue is on the horizon. Fortunately, the time periods are large, and even an incorrect decision made today could be rectified in 20 (or even 50) years without significant permanent harm.

We have also examined the economic motivations for increased resource recovery. Assuming acquisition of mineral rights via option-lease, the principal impact of greater recovery is felt via a change in the capital recovery factor, which declines as the mine life lengthens. A rough feeling for the magnitude of the impact may be obtained by analyzing the 2.0 million ton/year longwall mine described by Bickerton (1980). If the required return is 15 percent and the effective Federal tax rate is 50 percent, recovering the $\$ 100$ million investment over 40 years instead of 20 years, reduces the capital recovery factor by about 0.01 , and the minimum acceptable selling price by approximately $\$ 1 /$ ton. Clearly, the economic incentive for an operator to conserve the resource is rather weak.

In light of the above discussion of intergenerational equity, and the economic motivation to conserve coal, we conclude that there is no defensible basis for requiring an advanced mining system to achieve a recovery factor substantially in excess of the capability of current technology. 


\subsubsection{Statement of the Conservation Requirement}

4.1.3.1 The Conservation Systems Requirement is Stated as a Constraint. THE ADVANCED EXTRACTION SYSTEM WILL HAVE A CONSERVATION PERFORMANCE AT LEAST AS GOOD AS EXISTING EQUIPMENT OPERATING IN COMPARABLE CONDITIONS. The purpose of this section is to identify the preferred set of conditions for each of the existing technologies and then estimate a recovery ratio for this combination of technology and conditions.

The first step in developing a table of target recovery ratios is to assess the relative attractiveness of each technology for the range of conditions found in the primary resource--flat lying seams of moderate thickness. An examination of the relative attractiveness of the four underground technologies now in use in the United States suggests that the conditions which discriminate most sharply among the various technologies are the following:*

(1) Depth of overburden,

(2) Seam thickness,

(3) Regularity of the seam (i.e., absence of partings, roof and floor rolls, faults, etc.),

(4) Relative cavability of the roof, and

(5) Relative stability of the immediate roof.

We have examined all possible combinations of either "favorable" or "unfavorable" sets of these five conditions, and identified the preferred technology if one exists. Figure 6 presents the results of this analysis, which may be summarized as follows:

(1) Caving systems are designated as baseline technology for depths over 1500 feet, with the proviso that the roof must be cavable; no known baseline technology is available if the roof is not easily cavable.

(2) For depths exceeding 1500 feet, with cavable roof, longwall is preferred if the seam is very regular; if the seam is irregular shortwall is preferred for stability; otherwise, longwall is the baseline technology.

* Table A-1 in Appendix A presents a judgmental evaluation of the relative attractiveness of four technologies now in use in the United states for a variety of expected mining conditions. These judgments are based in part upon previous assessments by Stefanko (1977), Cominec (1975), and Kuti (1975). 


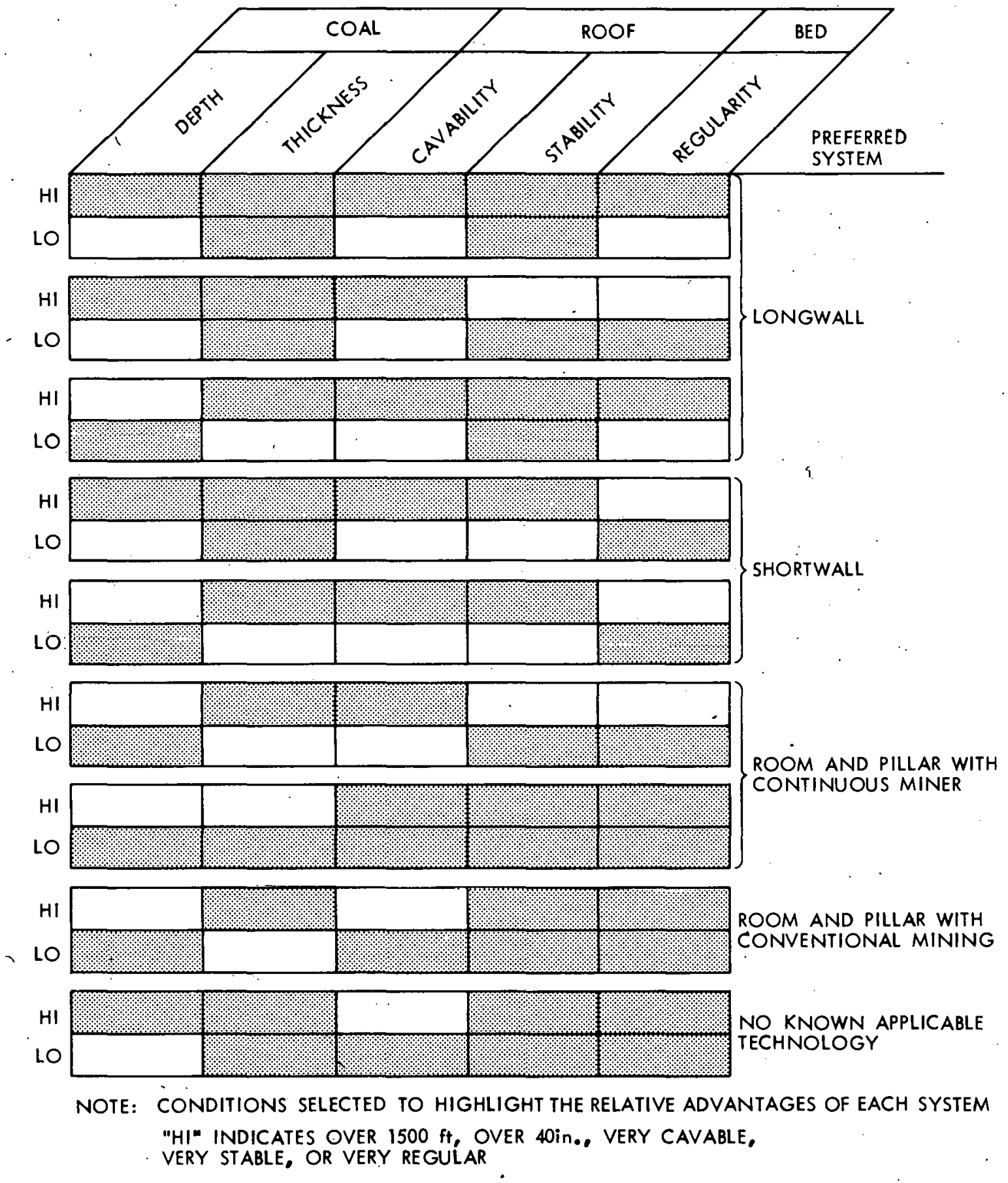

Figure 6. Preferred Technology for Various Combinations of Mining Conditions 
(3) For shallow depths (less than 1500 feet), room and pillar with a continuous miner is the baseline technology for low coal (less than 40 inches).

(4) Conventional mining ("cut-and-shoot") is the applicable tachnology for high coal at shallow depths under roof that is not very cavable.

(5) Caving systems form the baseline for thick coal at shallow depths under easily cavable roof, unless the roof is very unstable and the seam is very irregular, in which case, room and pillar with the continuous miner is preferred; longwall is preferred for highly regular seams, and shortwall is applicable to irregular seams so long as the roof is stable.

Finally, recovery ratios for each technology-conditions combination were prepared from currently available data which included:

(1) Empirical analysis of recovery achieved from production panels only, as reported by Reese, et al (1978).

(2) Determination of the fraction of a model mine devoted to mains and submains as opposed to production panels, as described by Harris (1980).

(3) Estimates of recovery from the non-production panel portion of a property (analyses of model mines, plus consultations with mine operators).

Because of the need to set recovery targets appropriate for Central Appalachia, two different scales of operation were chosen: (1) A 250,000ton/ year room and pillar mine (the same mine used in the environmental impact and conservation impact analyses reported in companion documents), and (2) A 1,000,000 ton/year longwall or shortwall mine (scaled down from the mine used in the projection of a moving technological baseline).

Recovery results are presented, by technology, in Table 8 . These values represent minimum targets for an advanced mining system operating in the conditions specified in. Figure 6 .

\subsubsection{Method of Evaluation}

Although the primary thrust of the conservation requirement is high recovery from the seam being mined, protection of neighboring seams is also a matter of concern. Thus, it is recommended that any assessment of conservation performance address impacted coals throughout a property and not merely limit itself to a computation of the conventional recovery ratio, for which quantitative requirements have been set. 
TABLE 8

TARGET RECOVERY RATIOS FOR EACH MAJOR MINING TECHNOLOGY

\begin{tabular}{|c|c|c|c|c|c|}
\hline \multirow[b]{2}{*}{ TECHNOLOGY } & \multicolumn{2}{|c|}{ PRODUCTION PANELS } & \multicolumn{2}{|c|}{ MATNS \& SUBMAINS } & \multirow[b]{2}{*}{$\begin{array}{l}\text { AGGREGATE } \\
\text { RECOVERY } \\
\text { FACTOR }\end{array}$} \\
\hline & $\begin{array}{l}\text { FRACTION } \\
\text { OF MINE } \\
\text { AREA }\end{array}$ & $\begin{array}{l}\text { RECOVERY } \\
\text { FACTOR }\end{array}$ & $\begin{array}{l}\text { FRACTION } \\
\text { OF MINE } \\
\text { AREA }\end{array}$ & $\begin{array}{l}\text { RECOVERY } \\
\text { FACTOR }\end{array}$ & \\
\hline $\begin{array}{l}\text { Room and Pillar, } \\
\text { Continuous Miner: } \\
\text { Full Pillar Extraction* }\end{array}$ & 0.7 & 0.7 & 0.3 & 0.4 & 0.6 \\
\hline $\begin{array}{l}\text { Room and Pillar, } \\
\text { Conventional Mining: } \\
\text { Partial Pillar Extraction* }\end{array}$ & 0.7 & 0.5 & 0.3 & 0.4 & 0.5 \\
\hline Longwa $11 * *$ & 0.8 & 0.7 & 0.2 & 0.4 & $0.7^{* * *}$ \\
\hline Shortwall** & 0.8 & 0.7 & 0.2 & 0.4 & 0.6 \\
\hline $\begin{array}{l}* 250,000 \text { ton/year mine } \\
* * 1,000,000 \text { ton/year mine }\end{array}$ & 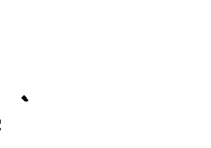 & & & & \\
\hline
\end{tabular}


The recovery ratio from the seam being mined may be easily obtained by analyzing a mine plan for a representative site. For consistency, this plan should be the same one used in assessing conformance with the other systems requirements. It is a simple matter to compute the fraction of coal recovered once the entry widths and pillar sizes have been determined, and a decision has been made on the proportions of coal to be recovered from pillars, barriers, and fenders. Reese, et al (1978) provides excellent guidance on the details of making such an analysis. Once this analysis is complete, a parameter study should be made to determine the sensitivity of in-seam recovery both to mine size and to variations in geology which span the range of conditions for which the candidate system is suited.

Estimation of impacts on. neighboring seams is considerably more difficult. Four types of impact can be defined:

(1) Rubbilization of nearby seams due to cavity collapse;

(2) Increased stress concentration and reduced roof competence due to mining out an overlying seam;

(3) Seams badly jointed but top and bottom surfaces remain fairly continuous; this phenomenon occurs in the region between the rubbilized zone and the pressure arch, and in subsidence zones; and

(4) Seams not discernibly impacted, i.e., seams lying above the pressure arch.

The appropriate categorization of coals at the representative site can be made once the extent of the rubbilized zone, pressure arches, and subsidence troughs are calculated. Empirical formulae suited for these purposes, as well as other information pertinent to these calculations, may be found in Harris (1980) and Stingelin, et al (1976). Given the coal tonnages in each category, it is a straightforward matter to compute the fraction of coals adversely impacted (categories 1, 2, and 3, plus coal left in the seam being mined).

\subsection{ENVIRONMENTAL IMPACT \\ 4.2.1 Introduction}

The environmental impact of coal mining has long been considered important. Sullivan (1980) has evaluated the modes of impact commonly experienced. It is felt that several factors make impractical the formulation of specific quantitative environmental requirements. First, the environmental impacts associated with mining are determined by the interaction between the mining system and the specific site being mined. Second, many environmental impacts are the result of a mine existing and are independent of the particular system being used; for example, any underground mining system will. result in generation of refuse and alteration of ground water flow. To 
propose specific environmental requirements not associated with the site would be impractical.

There is no fundamental way of determining how much environmental degradation is acceptable. In practice, the level of damage is weighed against economic benefits by a political process. This is the origin of most environmental and other regulation, and represents a judgment. We will accept the fact that present environmental regulation pertaining to coal mining represents society's judgment (which can change). Thus, any mining system must mitigate effects, as required by law.

At this point, rather than put forth specific system requirements, two general requirements will be outlined which will serve as criteria against which systems will be judged. The methods by which proposed systems will be compared with existing technology will also be described. In addition, an estimate of costs commonly associated with current environmental impact mitigation practices will be presented. Finally, potential environmental problems to be considered in the development of advanced equipment will be described. This discussion will serve as a guide to system design by describing (1) how proposed systems will be evaluated, (2) the economic significance of environmental impact mitigation associated with mining, and (3) general guidelines to achieve environmental advance over existing technology.

\subsubsection{Statement of the Environmental Impact}

4.2.2.1 Requirements. An advanced system should minimize adverse environmental impact during mining operations and maintain land suitability for future use. Two system design requirements are proposed which reflect these objectives. The first requirement addresses the costs of mitigating environmental impacts which have a potential for degradation of off-site environmental quality. Required mitigation of potential off-site impacts is not a productive part of the mining enterprise. Consequently, innovation in system design which proportionally reduces these "non-productive" costs will result in a cost advantage over current systems.

The second requirement addresses the range of potential land uses of the mine site and adjacent lands following mine closure. The effects of mining upon subsequent land use potential are considered as on-site impacts which are dealt with during reclamation. Successful reclamation should maintain the surface value of the land at the pre-mining land value. Proportionate reductions in reclamation costs, while maintaining land value, are viewed as an advancement over current technologies. Thus we are able to state two environmental requirements:

I. AN ADVANCED UNDERGROUND MINING SYSTEM SHOULD NOT RESULT IN HIGHER COSTS OF OFF-SITE ENVIRONMENTAL IMPACT MITIGATION THAN THOSE ASSOCIATED WITH CURRENT MINING TECHNOLOGY. A DESIRABLE LEVEL OF PERFORMANCE IS A SIGNIFICANT COST REDUCTION OVER CURRENT TECHNOLOGY. IN ANY CASE, THE COST OF ENVIRONMENTAL MITIGATION IS ADDED TO THE MINING COST, SO THAT ANY TRADE-OFF BETWEEN PRODUCTIVITY AND ENVIRONMENTAL IMPACT IS MADE AUTOMATICALLY. 
II. AN ADVANCED UNDERGROUND MINING SYSTEM WILL MAINTAIN THE VALUE OF MINED AND ADJACENT LANDS AT THE PRE-MINING LAND VALUE, FOLLOWING MINE CLOSURE AND COMPLETION OF RECLAMATION. AGAIN, SITE RECLAMATION COSTS ARE ADDED TO THE LEVELIZED COST OF PRODUCTION.

4.2.2.2 Method of Evaluation. The mode of system evaluation used in assessing compliance with the environmental requirements employs contemporary mining technology as a standard of performance. Both contemporary and advanced underground mining systems can be evaluated in light of existing mitigation and reclamation technologies. Several assumptions underlie this approach. The first is that all potentially adverse environmental impacts can be mitigated to an acceptable level. If impacts cannot be mitigated to levels prescribed by law and regulation, it is assumed that the mining activity would be prohibited and the system will not be evaluated further. A second assumption is that the total cost of mitigating adverse environmental impacts to acceptable levels is a reasonable surrogate for the significance of the aggregated impacts. In adopting this approach, the need for assessing the relative importance of individual impacts is avoided.

In determining the impacts of a mining system upon the site and adjacent lands, it is assumed that either a land use plan exists or that the range of possible uses can be projected for the mining region. The assessment of the suitability of the mine site is performed within a specific use category, rather than for all possible uses. In using this approach, the designated or projected land use category is assumed to reflect public opinion concerning the most appropriate potential use for the land in question. The cost of reclamation can then be made on a consistent basis.

Evaluations will be comparative. To achieve consistency, actual sites representative of conditions in Central Appalachia will be selected; conventional mining systems and proposed advanced systems will be conceptually implemented at each of the selected sites. For Requirement I, environmental impacts associated with each mining system will be identified using the approach described by Sullivan (1980). After potential impacts have been identified, cost figures for their mitigation must be determined. For Requirement II, actual pre-mining land use and potential land uses as described by regional land-use plans will be identified for each mine site. Reclamation costs associated with returning the land to its original or planned use will be determined via methods similar to those employed to cost the mitigation of off-site impacts. This method of evaluation has been demonstrated by Dutzi, et al (1980).

4.2.2.3 Cost of Impacts. Cost estimation for mitigation of off-site environmental impacts associated with coal mining systems will be accomplished by methods and data developed by Doyle, et al (1974). This report describes a comprehensive analysis of pollution control costs associated with current coal mines in the Monongahela River Basin of West Virginia, Pennsylvania, and Maryland. Samples included a variety of mining methods, mine sizes, and pollution control measures. Although the data are specific to the Monongahela River Basin, the cost estimates are representative of Central Appalachia and other areas with similar topography, mine drainage pollution problems, and mining history. 
Cost of controlling mine drainage pollution, erosion, and sedimentation, which are the major causes of off-site environmental problems, are highly site-specific and dependent upon such variables as local geology, soil characteristics, hydrology, ground water flow, and amount of water allowed to enter the mine. These local variables result in a wide range of costs associated with environmental impact mitigation, even within a small and apparently homogeneous region. Three impact mitigation techniques (mine drainage treatment, mine sealing, and refuse bank sealing) are discussed here in order to illustrate the range in mitigation costs.

Mine drainage treatment costs vary considerably according to method of treatment chosen and amount and quality of the water to be treated. According to Doyle, et al (1974), the installed capital costs for a sample of 10 mine drainage treatment plants range from $\$ 9,850$ to $\$ 1,094,000$ in 1971 dollars. EPA (1975) indicates that mine drainage treatment costs per ton of coal mined range from $\$ 0.03$ to $\$ 0.10$ in 1975 dollars (EPA-240-1-75-0586). Costs of mine sealing are affected by condition of the opening, condition of the rock, overburden thickness, hydrology, accessibility, haul distances, type of seal to be constructed, and number of seals. Doyle, et al (1974) report that the cost of a single mine seal can range from $\$ 2,100$ to $\$ 21,000$. Refuse bank reclamation, including clearing and grubbing, contouring, grading, soil cover, and revegetation, costs an average of $\$ 4,200 /$ acre.

The most significant impacts of mining activity on land value are the disposal of refuse and land subsidence. Generally speaking, refuse piles or fills are judged to be liabilities due to potential instability and effect on water quality. Non-uniform or unplanned subsidence can result in land being made unsuitable for urban and agricultural uses.

Dutzi, et al (1980) performed a site-specific analysis of a contemporary room and pillar mine at a site in Clay County, which appears to be representative of Eastern Kentucky. Environmental impact mitigation, including sediment control, water treatment, mine sealing, and revegetation of disturbed areas, was estimated to cost from $\$ 0.04$ to $\$ 0.05 /$ ton of coal mined. Before mining, the site was covered with natural forest and had no urban or agricultural uses. According to Reynolds (1979), values of such lands without mineral rights in this part of Kentucky range from $\$ 150$ to $\$ 250 /$ acre. No land-use plan exists for this region, so it was assumed that the land would be returned to its original use (i.e., forest land). General reclamation for the site, including removal of access roads, backfilling all disturbed areas to original contour, soil cover, refuse bank grading and soil cover, and revegetation, constituted a minor portion of the total cost of environmental. impact mitigation (less than $\$ 0.01 /$ ton of coal mined).

4.2.2.4 Design Guidelines. Water quality degradation is a significant problem associated with underground mining. Acid mine drainage (AMD) occurs in many parts of Central Appalachia. AMD is caused by oxidation of ferric materials in the coal itself or in the surrounding rock. Water cannot be prevented from entering a mine, and hydraulic sealing of a mine is often 
ineffective. Liquids contained in a mine will ultimately reappear. Thus, Laird (1979) cautions that control of the movement of water during and after mining is not a realistic requirement. However, it is sometimes possible to restrict the movement of air into the mine and thus retard or arrest oxidation through complete collapse of the mine roof. Systems which can achieve uniform and complete subsidence are likely to have fewer AMD problems in areas where AMD is a consideration.

Systems which rely on the use of potentially toxic working fluids in the mine are likely to be penalized in an environmental assessment. For example, it is possible that solvents might be used in cutting. As noted, liquids cannot always be effectively contained, and will reappear elsewhere. In areas where AMD is a problem, even the use of water as a cutting agent could present significant problems.

Control of sediment is another major water quality concern. Production of sediment by a mine is a function of the area disturbed by the total mining activity, the magnitude of surface flow disruption, amount of runoff, and the volume of water pumped from the mine. Generally, the largest portion of the sediment is derived from access or haulage roads. Parker (1979) indicates that reduction of the area covered by roads through the use of alternative haulage methods would present a definite advantage over existing techniques.

Refuse piles are an important source of sediment and potentially toxic materials. Moreover, they are also judged to have a negative impact on land value. According to Parker (1979), a desirable feature of an environmentally advanced coal extraction system would be underground disposal. of refuse. In addition to potential processing economies, underground disposal would reduce the possibility of negative land value impact, while possibly contributing to control of both subsidence and AMD. However, the potential for aquifier degradation must be considered for subsurface disposal schemes.

Finally, subsidence itself is of major importance in determining subsequent land value. Obviously, regular, uniform, and controlled patterns of subsidence are desirable in order that potential land uses not be restricted.

\subsection{MINER HEALTH}

4.3.1 Introduction

The coal mining industry has been considered inherently unhealthful because of the difficulty with controlling exposure to a wide variety of hostile working conditions. Furthermore, these conditions affect all the major physiological subsystems; the respiratory system, cardiovascular system, hormonal system, and sensory system (see, for example, Rockette (1977)). The key factors contributing to physiological degradation are dust (e.g., coal, quartz), methane gas, diesel emissions, poor lighting, noise, and vibration. In addition to these physiological factors, Lorenz (1966) points to the 
psychological problems resulting from working in small, closed, unlighted spaces. Therefore, it appears reasonable that any advanced coal extraction system should provide a substantial improvement in working conditions, either by making the mine environment more hospitable or by isolating miners from the environment.

Epidemiological studies comparing the incidence of various diseases in coal miners to the general population, indicate that respiratory disease is the primary factor contributing to mortality and early disability. Rockette (1977) indicates that where other diseases do exist (such as malignancies, diabetes, and cardiovascular disorders), their relative frequencies are not significantly different from the general population. This is evident in Table 9. Therefore, it is apparent that the major thrust of the health requirement should be reduced exposure to elements in the underground mining environment that contribute to respiratory disorders.

\subsubsection{Statement of the Health Requirements}

Rockette (1977) reports coal worker mortality rates which are not significantly in excess of the rest of the general male population (i.e., approximately 3 percent). Clear evidence of this can be seen graphically in Figure B.1-1 of Appendix B. Consequently, it appears that a better measure of the potential impact of a new extraction system on health, would be some indication of the ability of the system to reduce the incidence of respiratory related disability among coal miners. Research by Morgan (1975), Nacye (1971), and others indicates that these respiratory problems are caused by dust and aggravated by high temperature and humidity. Therefore, the primary health requirement is to remove or protect the workers from these major contributors to pulmonary disease. Secondary requirement address additional elements in the environment that affect other bodily functions, (e.g., lighting, work space, vibration, and noise).

\subsubsection{Primary Health Requirements}

Research reported by King (1960), Morgan (1975), Nacye (1971), Penman (1970) and others indicates that the onset and development of coal worker's pneumoconiosis (CWP) and progressive massive fibrosis (PMF) is dependent on the presence of coal dust of particle size less than 5 microns in the mine atmosphere. Recent discussions with Drs. Stuermer and Hatch (1980), of Lawrence Livermore Laboratories, indicate mutagenic compounds (such as aromatic hydrocarbons) can potentiate the occurrence of CWP, PMF, and other kinds of lesions.

Rockette (1977) notes that cigarette smoking is a habit common with miners, and known to be a contributing factor in contracting CWP. Although coal workers with CWP frequently do not show a significantly altered ventilatory capacity, they do exhibit a marked decrease in oxygen transfer. A failure of the pulmonary system to transfer oxygen at at least $1250 \mathrm{cc} / \mathrm{min}$ prevents an individual from being gainfully employed in an occupation which requires continuous moderate physical activity. Rasmussen (1970) established a relationship between the concentration of coal dust of greater than 5 micron 
TABLE 9

OBSERVED COAL MINER DEATHS, COMPARED WITH EXPECTED

DEATHS FOR ALL U.S. MALES, FOR SELECTED DISEASES

(Data from a Sample of 22,998 Coal Miners)

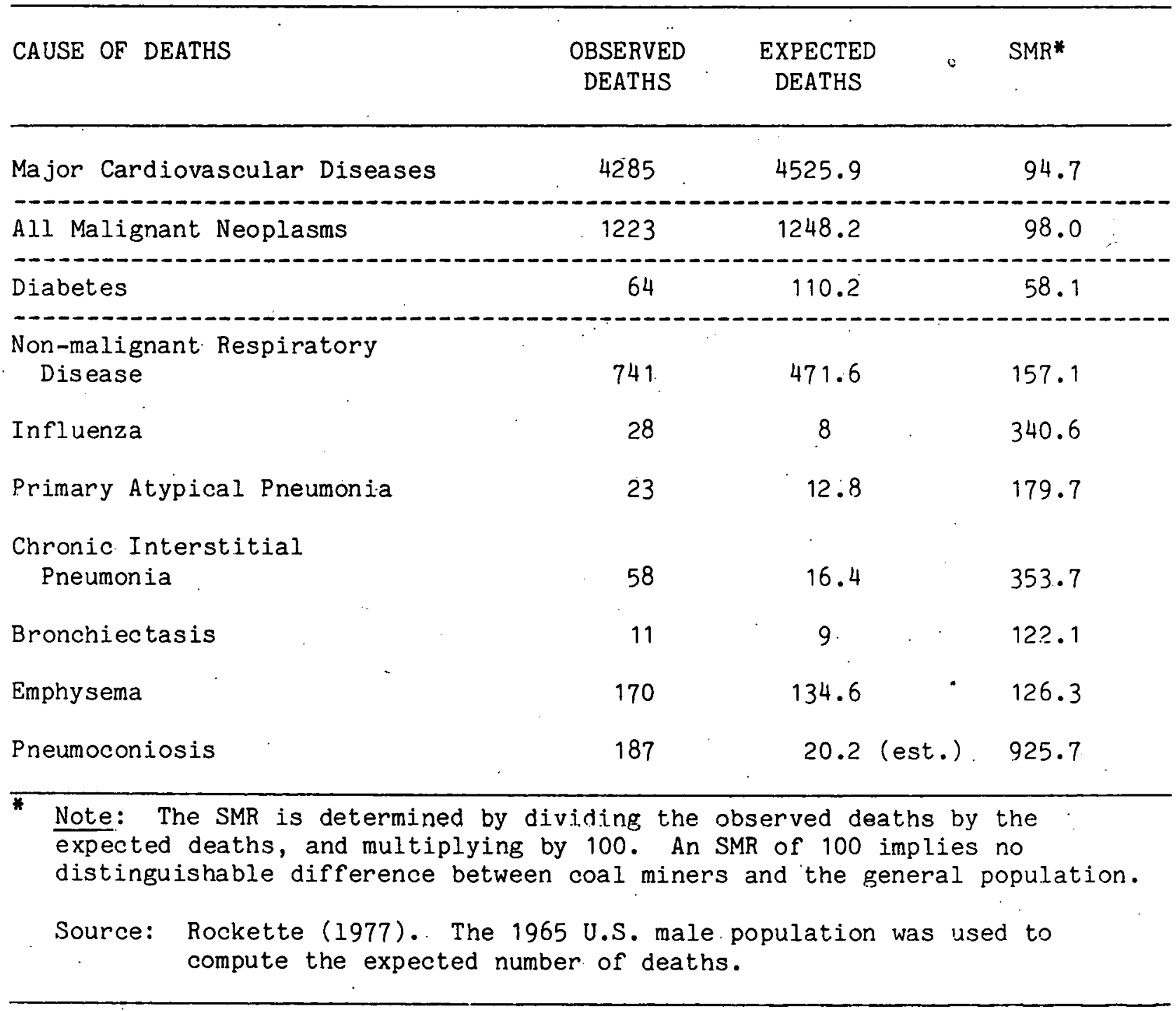


particle size and chronic bronchitis which is known to be excessive in coal miners. In sum, there is ample evidence that a reduction in coal dust concentration will diminish the incidence of CWP, PMF, and bronchitis and thereby lessen excessive coal miner morbidity. in comparison to the rest of the working population. A more complete physiological discussion of these diseases and the contributing factors may be found in Zimmerman $(1980 \mathrm{C})$. 1

- Davies (1974) and Lyons, et al (1972) have shown that the actual susceptibility of miners to CWP or PMF varies widely in both the exposure time and the allowable threshold. However, there is good agreement between health experts in both the Department of Labor and the United Mine Workers that exposing workers to no more than two milligrams per cubic meter of dust at all locations in the mine would greatly reduce the incidence of respiratory disability. Maintenance of this maximum level of exposure is now required by regulation, and therefore, forms the basis for the primary health requirement on an advanced system (see Title 30 of the Federal Code of Regulations). Thus, the primary health requirement can be stated as follows:

ADVANCED COAL MINING SYSTEMS MUST NOT EXPOSE MINERS TO DUST LEVELS HIGHER THAN TWO MILLIGRAMS PER CUBIC METER. THE COST OF MITIGATION MUST BE ADDED TO THE PRODUCTION COST OF THE COAL PRODUCED.

Establishment of requirements on exposure to known carcinogenic, mutagenic, and toxigenic compounds is difficult due to the wide variation in susceptibility of workers to related disorders. In consequence, no standard can be set at this time. Moreover, advanced systems may introduce compounds into the mining environment that are equally dangerous yet different from the list of compounds known to be unhealthful. Current research by Stuermer and Hatch (1980), indicates that there are four generic groups of mutagenic compounds which can be present in the mining environment. These are released through the mechanisms of heat and pressure, or in combination with solvents. Because we cannot assign defensible threshold levels, the safest course is to require that workers not be exposed to any of these compounds in the course of performing their tasks.

\subsubsection{Secondary Health Requirements}

The underground mining environment frequently has a high humidity. It is well documented that a high humidity atmosphere increases the likelihood of developing bronchospasm in susceptible individuals (see, for example, Fraser (1977) and Heitzman (1973). The suspected unhealthful effects of prolonged exposure to high humidity in a mine is corroborated by the statistically high incidence of asthma among underground coal miners, as reported by Rasmussen (1970). This health problem is discussed in more detail by Zimmerman (1980b).

In addition, although no quantitative relationship can be determined from the data available, Rasmussen (1970) argues from theoretical considerations that temperature extremes, as well as humidity extremes, will seriously increase the development of respiratory disease among underground coal miners. Thus, any new system should attempt to reduce exposure to high 
humidity and temperature extremes in order to promote the general pulmonary health of miners.

ANY NEW TECHNOLOGY SHOULD ATTEMPT TO CREATE AN ATMOSPHERE WHERE THE RELATIVE HUMIDITY IS BETWEEN 50 PERCENT TO 75 PERCENT AND THE TEMPERATURE IS BETWEEN $65 \mathrm{~F}$ AND $78 \mathrm{~F}$ WITH NO PROLONGED EXCURSION OUTSIDE OF THESE LIMITS.

Other environmental factors which affect health are: (1) lighting, (2) noise, (3) working space, and 4) vibration. Requirements for lighting and noise are well documented. Experience in other industries, as well as current research in mining, suggests that any advanced system should comply with the following design requirements for working space and vibration:

4.3.4.1 Working Space. Human engineering studies pertaining to operator performance under varying space and vehicle control constraints, have indicated a direct relationship between fatigue, cramped working space, and poor positioning of controls. Studies done on the psychological effects of operating in cramped space (see Lorenz (1966)) also imply a relationship between irritability, fatigue, and limited working space. The mining environment cannot practically allow for ideal working space conditions. Nonetheless, it is recommended that at a minimum, advanced systems be designed with consideration given to established anthropometric standards. The basic standards are summarized by Zimmerman (1980b).

4.3.4.2 Vibration. Prolonged exposure to vibration from equipment can result in "vibration disease."* This condition is characterized by: a reduction in pain sensation, decrease in vibration sensation, pains in the joints (particularly the hands), hyperactivity; and decrease in libido. As the threshold for these effects varies widely by individual, it is difficult to set a design standard for acceptable machinery vibration levels. Nonetheless, advanced systems should be designed to include vibration supression equipment. For ease of reference, all the primary and secondary health requirements developed above are summarized in Table 10.

\subsubsection{Method of Evaluation}

The major problems with evaluating health hazards on new designs are that: (1) levels of exposure are difficult to predict in a rigorous. way, and (2) effects of exposure are poorly understood and do not show up for a long time. Therefore, it is necessary to evaluate new technology, and measure the compliance with requirements, in a fairly subjective way.

As described in a separate report by Zimmerman (1980b), the evaluation is divided into two steps. The first step starts with a complete operational analysis of the system. Here, the system is examined to understand how the coal is cut, how the face is ventilated, how the coal is hauled, how the roof is supported, and what are the salient aspects of the

\footnotetext{
* See Paranko, et al (undated).
} 
TABLE 10

SUMMARY OF ADVANCED COAL EXTRACTION

SYSTEM HEALTH REQUIREMENTS

\begin{tabular}{|c|c|c|}
\hline $\begin{array}{c}\text { HEALTH } \\
\text { CHARACTERISTICS }\end{array}$ & GOAL & REQUIREMENT \\
\hline \multicolumn{3}{|c|}{ PRIMARY REQUIREMENTS } \\
\hline Dust & $\begin{array}{l}\text { Reduce miner mortality } \\
\text { and morbidity resulting } \\
\text { from lung disease to that } \\
\text { of U.S male population }\end{array}$ & $\begin{array}{l}\text { No greater than } \\
2 \mathrm{mg} / \mathrm{m}^{3}\end{array}$ \\
\hline $\begin{array}{l}\text { Carcinogens and } \\
\text { Mutagens }\end{array}$ & Same as abovè & $\begin{array}{l}\text { Concentrations no } \\
\text { greater than that in } \\
\text { air of large unban } \\
\text { areas }\end{array}$ \\
\hline \multicolumn{3}{|c|}{ SECONDARY REQU IREMENTS } \\
\hline Temperature & $\begin{array}{l}\text { Permit miners to work } \\
\text { in environment satisfying } \\
\text { OSHA and MSHA standards } \\
\text { for other industries }\end{array}$ & $\begin{array}{l}\text { Between } 65^{\circ} \mathrm{F} \text { and } \\
\text { and } 78^{\circ} \mathrm{F} \text { with no } \\
\text { extreme swings }\end{array}$ \\
\hline Humidity & Same as above & $\begin{array}{l}\text { Between } 50 \% \text { and } 75 \% \\
\text { with no extreme } \\
\text { swings }\end{array}$ \\
\hline Noise & Same as above & Meet MSHA standards \\
\hline Lighting & Same as above & Meet MSHA standards \\
\hline Working Space & Same as above & $\begin{array}{l}\text { Accomodate most body } \\
\text { configurations }\end{array}$ \\
\hline Vibration & Same as above & $\begin{array}{l}\text { Provide vibration } \\
\text { damping for machinery } \\
\text { operators }\end{array}$ \\
\hline
\end{tabular}


working environment. In addition to the operational analysis, a task time analysis is conducted to establish the amount of interaction of the workers with the various operational elements. Once this information is assembled, all of the system components are compared with similar contemporary systems (not necessarily mining systems) to determine whether the new system may generate the same health hazards as contemporary systems, whether new health hazards have been introduced and whether exposure to these health hazards will be reduced. In this analysis, reduced exposure to health hazards (as in a dust containment system) is as important as elimination of a hazard (reduction of dust via jet cutting).

The second step requires a subjective assessment of the kinds of design changes and alterations in worker protection that show promise of meeting the system requirements on exposure. Five levels of compliance with the requirements may be distinguished: beneficial effect; uncertain, but likely to be beneficial; no effect; uncertain, but likely to be a detrimental effect; or a detrimental effect. These judgments are obtained via consultation with experts in the field of occupational health who are provided with the data on system operation, identified health hazards, and projected exposure levels. As there is no way to quantify precisely how much dust will be generated, or the volume of toxic fumes emitted, it is necessary to identify the presence of the various health hazards and place a subjective weight on the ability of the design to minimize the hazards. Although non-quantitative, this approach offers an organized method of comparing new designs against existing technology.

\subsection{MINER SAFETY}

\subsubsection{Introduction}

Coal mining is regarded as one of the more hazardous occupations in the United States. This can be substantiated by the known rates of temporary and permanently disabling injuries and fatalities in mining, as compared to other occupational categories. Table 11 presents a summary of injury statistics complled by the U.S. Department of Labor for the period 1972 through 1978. The data of Table 11 suggest that mining is not enormously more dangerous than other industries in terms of total injuries, but that the rate of serious injury and death is a factor of two to three higher.

Analysis of injury data by MSHA indicates that the major hazards contributing to the rate of injuries and fatalities in coal mining have been (1) roof or face falls, (2) slips and falls, (3) electrical burns or shocks, (4) fires and explosions, (5) unsafe handling of material, (6) impact by machinery, and (7) being pinched or squeezed by equipment. The major factors mediating the impact of these hazards are the time an individual worker is exposed, the amount of body protection, the number of people exposed in a confined area, and the unpredictable nature of the mining environment.

\subsubsection{Statement of the Primary Safety Requirement}

In light of the above analysis it appears that the systems requirement for safety should focus primarily on the reduction of deaths and 
TABLE 11

AVERAGE INJURY RATES IN SELECTED INDUSTRIES

FOR THE PERIOD 1972 THROUGH 1978

Sources: MSHA injury statistics (1971-1979)

OSHA injury statistics (1972-1978)

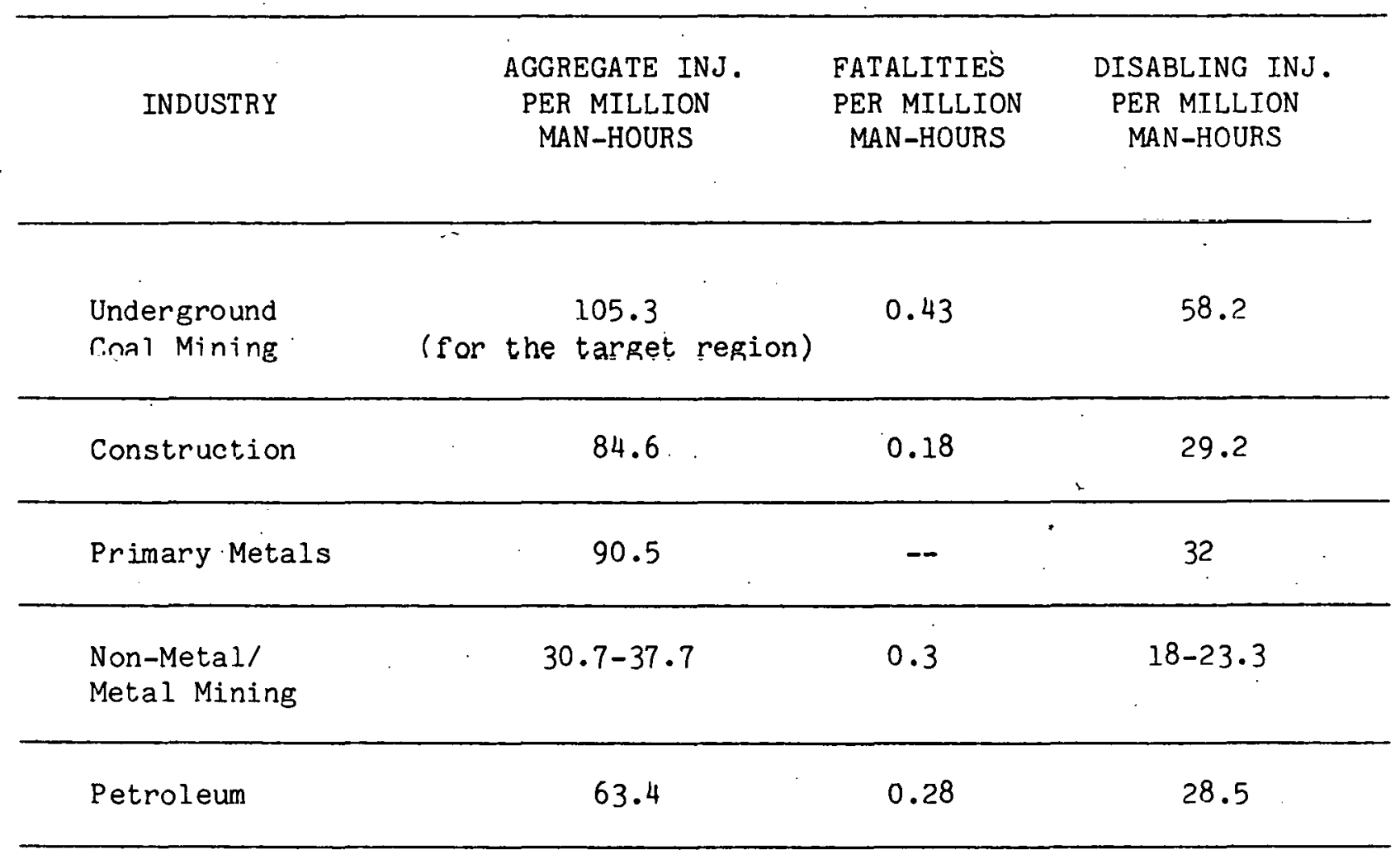


disabling injuries and secondarily on the reduction of total injuries. In setting quantitative goals, we pursued two different approaches: (1) seek a statistically significant reduction in underground coal mining injuries or, (2) require that underground coal mining match the safety performance of some set of comparable industries. In practice, the two approaches yielded very similar numerical results. We selected the second approach (comparable industries) because the first approach requires an arbitrary choice of the percent reduction needed to achieve a statistically significant difference. The four industries listed in Table 11 were chosen as comparable because of their similarity to mining in terms of both the types of hazards encountered and the severity of accidents which occur.

However, examining the seven year average for these industries does not give the complete picture. It would not be reasonable to set an overall safety requirement without considering the possibility that in the year 2000 coal mining, as well as other industries, may have significantly different injury rates. In fact, if one examines the trends of the above industries (see Appendix C.1), it is clear that the aggregate injury rate for coal mining is already within the range of the four industries chosen as comparable. In particular, the coal mining trend appears to be approaching a range of 65-75 injuries/million man-hours in comparison to $25-85$ injuries/million man-hours for similar industries. However, the yearly fatality and disabling injury rates for coal mining have consistently been approximately two times higher than the industries selected as comparable.

In sum, the safety requirement should stimulate a reduction in deaths and disabling injuries and must be stated in a way to allow for long term trends in both coal mining and the designated set of comparable industries. These ideas lead to the following statement of the requirement:

\section{AT THE ANTICIPATED TIME OF FIRST COMMERCIAL USE, ANY ADVANCED UNDERGROUND COAL MINING SYSTEM MUST HAVE RATES FOR FATALITIES, DISABLING INJURIES, AND TOTAL INJURIES WHICH FALL WITHIN THE RANGE OF RATES EXPERIENCED BY INDUSTRIES WHICH ARE JUDGED TO HAVE COMPARABLE HAZARDS.}

The requirement, as stated requires a projection for all three categories of injuries. Examination of the fatality and disabling injury ratios reveals no trend for coal mining or for any one of the comparison industries. Therefore, we will project the fatality and disabling injury requirement by extrapolating the experience of the seven year period 1972 through 1978. Total injuries will be projected by using the trends presented in Figures $C \cdot 1-1$ and $C .1-2$ (Appendix $C$ ), and by assuming that the ratio of severe and disabling injuries to total injuries will remain constant at the values shown in Table 12. This analysis yields the following target rates for Central Appalachia in the year 2000:

(i) Total injuries: 40-45/million man-hours

(2) Disabling injuries: $30 /$ million man-hours

(3) Fatalities: $0.2 /$ million man-hours 
TABLE 12

DISTRIBUTION OF FATALITIES, DISABLING INJURIES, AND NON-DISABLING INJURIES IN UNDERGROUND

COAL MINING FOR THE YEARS

1971 THROUGH 1978

Source: Annual statistics on injuries

compiled by the Mine Safety and Health

Administration, U.S. Department of Labor

Injury Category

Fatalities

Disabling, Non-Fatal

Injuries

Non-Disabling

Injuries
Percent*

$$
0.5
$$

61.3

38.2

Total $\quad 100.0$

* Note: Even though the overall injury ráte for coal mining is decreasing, the above percentages remain relatively constant.

These targets are based upon projections which may prove to be pessimistic as the baseline technology evolves. Indeed, considering the length of time required to develop, test and introduce a new system, (i.e., 10-15 years), it is quite possible that the baseline technology will satisfy all aspects of the safety requirement. In that case, advanced mining systems would not need to possess advantages in safety performance.

A caveat should be expressed concerning this method of characterizing system safety performance. Incidents per million man-hours is useful for comparing mining to other industries, however, it masks the overall impact on society. Consider a system which does not reduce the man-hour injury rate, but results in a lower injury rate per ton due to greatly increased labor productivity. Socially, coal now costs fewer injuries, but our index shows no improvement.* No simple resolution of this difficulty can be made.

* There is evidence that the converse situation has evolved following the passage of the Coal Mine Health and Safety Act of 1969: Injuries per million man-hours are lower, but, because of lower labor productivity, injuries per ton have increased somewhat over the pre-1969 level. 
4.4.3 Secondary Safety Requirements

In selecting opportunities for improving safety performance, available data suffice to identify which hazards are presently most severe. Examination of fatality and disabling injury rates for Central Appalachia for all the various hazard categories indicates a consistently high yearly contribution from roof and face falls, haulage accidents (mostly in the form of pinch and squeeze injuries), other machinery related accidents, and injuries sustained while handling material. According to MSHA statistics, these four hazards have continually accounted for at least 75 percent of all disabling injuries during the period 1971 through 1978. Therefore, it appears that the designer of an advanced system should consider reducing the incidence of these existing hazards in any attempt to meet the injury rates which form the primary safety requirement.

\subsubsection{Method of Evaluation}

It will be necessary to estimate the expected performance of a proposed system long before actual operating experience can be evaluated. Otherwise the system requirements will be of no value in determining research and development priorities. Such a safety evaluation method has been created by JPL, and is separately reported by Zimmerman (1980a). A summary is given here.

The analytical approach is divided into two phases. The first starts with a complete system failure analysis. This initial step is important because an advanced system may have a different architecture than existing equipment, and therefore, different failure modes. This information is the basis for the next step, the system hazard analysis. Both isolated and large-scale accident modes will be included.

The matching of system failures with potential human interfaces is done considering all factors related to system operation. These factors include possible adverse weather, hostile geology, machine failures, and human error. In this manner one attempts to identify and describe all potential hazards to which workers will be exposed in the performance of their tasks. In addition to the system hazard analysis, data are assembled on task times and descriptions, production rates, crew sizes, protective devices, and machinery redesign possibilities.

At this stage, a suitable comparison is chosen from existing technology. This similarity can be functional or non-functional in nature. Functionally similar systems are those which operate in a similar environment and operate in the same fashion (e.g., both extract coal using a boring process). Non-functionally similar systems are those which have only one thing in common, (e.g., they are both material handling machines with the existing hardware being used to load ore boats). This type of comparison is used when it is not possible to find a mining analogue for some portion of the advanced system. The same data pertaining to task times, production rates, crew size, etc., are collected for the contemporary equipment selected for comparison. In addition, historical injuries related to the major hazards associated with the various conventional tasks are also tabulated. 
Next, the two systems are compared from the standpoint of hazards, and the fractional reduction (or increase) in exposure times, people exposed, and body protection afforded. For each task, man-hours at risk are multiplied by the injury rates observed for analogous equipment, and then total system safety performance is estimated by aggregating the rates for the various tasks.

Phase two of the evaluation involves an interview process, during which experts conversant with coal mining safety are provided all the above comparative data and asked for an estimate of injuries based on their experience. This approach is deemed reasonable considering that the degree of exposure to a hazard and the resultant number of injuries, are not necessarily directly proportional to each other, and that some hazards interact with each other to increase exposure. Therefore, combining expert judgment with the projected injury estimates provides a more accurate depiction of system performance.

The experts are asked to make an initial judgment on the injury rates expected for the new system by considering: (1) the system design, (2) a comparison of hazards between the two systems, and (3) existing injury levels. If so indicated, the equipment or operating procedures are redesigned, and new hazard projections are made. The experts are provided the new data on projected injuries and asked to modify their original estimates until a final "range" of expected system injuries is reached. The final consensus on expected system performance is then compared against the requirement to measure the degree of compliance.

\subsubsection{Economic Trade-Off Considerations}

Present expenditures for fatalities and disabling injuries indicate that less than one dollar out of the price per ton of coal is actually spent for total compensation. Even if compensation were increased with further internalization of the social cost of death and injury, it appears that the cost of safety would still be a relatively small part of operating costs. Appendix C.2 provides a more detailed discussion of the cost of safety in comparison with operating costs.

This does not mean that safety is not an important factor in the design of advanced extraction systems. It does mean that the cost of safety (given that the new system is close to meeting the prescribed requirements) need not be traded off against performance. That is, the requirement for safety exists apart from economic issues, and is socially derived. The cost of providing an appropriate level of safety is simply added to the cost of the coal produced. The validity of this approach can be easily demonstrated. Suppose we estimate the cost of accidents today to be as much as say, $\$ 3 /$ ton. Two advanced systems are being compared. One reduces the cost. of coal by $\$ 3 /$ ton while not reducing accidents, the other achieves no reduction in cost, but eliminates accidents. While the comparison is presumably a wash in terms of dollar costs, there is little doubt which mining system would be chosen. 
In previous sections the goals for advanced performance in miner health and safety, environmental impact, and conservation have been identified. A second and more important thrust for the advanced system is to design new hardware incorporating performance advances that will be commercially attractive to the industry.* In short, commercialization is viewed as the ultimate goal of the program, and production cost or profitability comparisons with contemporary technology will be an important consideration in judging the commercial attractiveness of a new system. Accordingly, the production cost requirement must be set with commercialization in mind.

In this document, production cost is understood to include all of the out-of-pocket expense and a normal profit, as reflected in a minimum acceptable selling price. To be acceptable to the operator, this price must cover reasonable payments to the debt and equity holders. In addition, this minimum price must cover all of the internalized costs of assuring a safe, healthful workplace, and mitigating adverse environmental impact. Conservation performance, narrowly defined, impacts cost as well, principally through the capital recovery factor in those cases where mineral rights are leased, not purchased outright. With other factors held constant, the higher the recovery, the lower the capital cost per ton over the life of a mine. In sum, production cost is impacted materially by either the need or the desire to meet certain levels of performance in the areas of environmental impact, miner health and safety, and coal recovery.

Accordingly, production cost is a good overall measure of system performance, to the extent that it does reflect responsible management practice and compliance with regulations. More formally, production cost may be used (1) to aggregate the internalized cost of meeting the constraint levels set for the other requirements, and (2) to assess the cost impacts of achieving higher goals for safety or other attributes. Inevitably, however, this operator-oriented view of cost excludes certain factors such as:

(1) society's need to cope with an abandoned leaky mine seal which was constructed according to best available technology;

(2) the external social costs of fatalities, disabling injuries, and impaired health, which resulted in spite of both the designer's and operator's best efforts to provide a safe, healthful workplace, according to regulation;

(3) possibly higher energy costs for future generations as a result of permitting current economics alone to dictate level of recovery, or the mineability of unrecovered coal.

*White (1978) presents a recent industry perspective on the characteristics of an innovation, which a priori favor commercial success. 
These issues, although important, are not accounted for in production cost as defined for the purposes of judging commercial merit. Recognizing their importance, we have discussed these and other issues of similar nature elsewhere in the document.

\subsubsection{Factors Involving Time and Risk}

There are three general groups of factors to consider in setting a cost requirement: (1) the long lead time from conceptualization to commercial use; (2) trends in the industry and society as a whole, and (3) the economic risks in developing and commercializing a new technology.

One should anticipate ten to fifteen years to develop, test and market a new mining system, plus up to another five to ten years before it enjoys substantial use by the industry. Both the market for coal, and the equipment available to the industry can change considerably over this period. Thus, the competition for new technology is not today's technology. Moreover, the price of coal to be used as a research and development target must consider the evolution of the demand for coal, and changes in the cost of transport from mine to market; interfuel substitution, etc. These long lead time effects can be handled via the concept of a moving baseline, whereby both improvements in mining technology and their cost implications, together with forecasts of future demand by end users are examined to project target prices for the resource in question. Because these price targets are based on a detailed scenario of how the hardware will evolve, they are called "bottom-up" targets. As a check on these bottom-up projections, one can separately forecast prices from a "top-down" analysis which incorporates aggregate forecasts of growth in regional demand; trends in pollution control regulations; changes in freight rates; the productivity changes due to resource depletion, technological progress, evolution of labor force experience, etc.

The trends in the industry and society as a whole point to increased mechanization and automation as a solution to many problems.* The industry, concerned about inflation, sees mechanization and the corresponding productivity increases as a way to meet the impact of continually rising wages and benefits. It is reasonable to expect coal miners' wages to rise more rapidly than the wages received by the average manufacturing worker, in view of the significantly higher health and safety risks and generally unappealing working conditions, coupled with increased mobility and rising expectations within the traditional sources of mine labor. Recent legislation and

- regulatory authority, plus a generally more assertive and independent posture of those entering the workforce in the. $70^{\prime} \mathrm{s}$ and $80^{\prime} \mathrm{s}$ reinforce the factors which favor substantial increases in real labor cost.

*The reader is referred to an ensemble of articles treating this topic in Coal Age (July 1975). 
Risk is the final issue to be discussed as a background to setting a production cost requirement. Because we are dealing with new, possibly revolutionary technology, $r$ isk is the central cost issue. The question is, can risk be quantified, and if not, how should it be handled within the context of a system. requirement?

Before trying to answer this question, let us explore the nature of risk as a project progresses through the research and development cycle. At the beginning of a project, when it exists only as a conceptual design, technical risks predominate. A central concern is, will it work at all, which later gives way to will it work as designed? Once feasibility is established and the design is firm, manufacturing risk becomes the issue: can the machines be made on a production line basis for the cost projected by the designers? Will the equipment match the performance of the prototype in terms of both output and reliability? When the manufacturing problems are overcome, the focus shifts to the coal operator who will use the new equipment. The operator confronts a substantial applications risk: will the new machines live up to the manufacturer's promises of tons per machine shift and operating cost? What is the risk of an equipment failure jeopardizing the ability to meet contract deliveries and subsequently, financial obligations to debt holders? What is the possibility that this new equipment will, within its lifetime,. be made obsolescent by evolutionary development of predecessor technology, or by even more advanced machines now under development?

In theory, one could attempt to describe, quantify, and aggregate all of these various risk factors into one or a few carefully constructed figures of merit. Indeed, the practitioners of decision analysis do just that, with the degree of success being highly situation dependent.* In our view, decision analysis is most useful in those cases where there is one well defined locus of decision. In this case, the decision involves a wide spectrum of participants from both the public and private sectors, and thus, the practicality of a formal decision analysis is questionable, whatever its merits might be.

Another, traditional, approach to risk evaluation in such a case is break-even and sensitivity analyses, with searching examination of the possible negative factors, coupled with step-by-step, limited scope design, modeling, and experimentation, leading eventually to a laboratory mock-up, limited field trials, and finally demonstration test. As significant new information on feasibility and equipment performance is obtained, the production cost projections are refined, but no great amount of confidence is attached to these calculations until the demonstration test is complete and its results scrutinized. It appears to us that this second mode of handling risk is more appropriate to the development of a radically new mining system.*

* Hertz (1979) describes a formal procedure for treating risk in an explicit fashion.

* Frantz (1979) and Suboleski (1979) indicate a strong industry preference for this process-oriented way of dealing with risk. 
Before moving to a formal statement of the production cost requirement, it is useful to summarize the points made in the introductory discussion:

(1) Commercialization must be the primary consideration; with profitability set high enough to attract a substantial group of users.

(2) Profitability must be assessed against a moving target, with. production cost goals predicated on reasonable projections of equipment capability 10 to 20 years into the future.

(3) Although quite important, near term profitability is not the only consideration: insulation from continuing labor cost inflation, plus the ability to cope with the risks inherent in new technology are major concerns of the potential user.

(4) Finally, the assessment of economic risk as seen by an operator 10 to 20 years hence must figure explicitly in the production cost requirement -- in effect, the evaluation of risk is at the heart of this requirement. However, any quantification of rișk must be appropriate to the incomplete data and many unresolved issues characteristic of the early stages of systems definition and development.

\subsubsection{Statement of the Production Cost Requirement}

Development of a commercially acceptable system is the primary goal of the advanced mining system program, and production cost advantage is presumed to be the major determinant of commercial attractiveness. The statement of the requirement itself will be immediately followed by necessary definitions and clarifications which, taken together, will provide the rationale for the requirement. This is followed by a brief description of how to evaluate system performance against the requirement.

ANY ADVANCED MINING SYSTEM WHICH IS A SERIOUS CANDIDATE FOR DEVELOPMENT AS A COMMERCIALLY ATTRACTIVE MEANS OF EXTRACTING A SPECIFIED KESOURCE, MUST SHOW PROMISE OF YIELDING A RETURN ON INVESTED CAPITAL (ROI) OF AT LEAST 1.5 to 2.5 TIMES THE MINIMUM TARGET ROI REQUIRED BY THE INDUSTRY FOR ITS AVERAGE CAPACITY EXPANSION OR REPLACEMENT PROJECT AT THE PROJECTED TIME OF FIRST COMMERCIAL USE.

\subsubsection{Definitions and Clarifications}

4.5.3.1 Mining System. The system includes mine design, site and seam access, initial development, the period of nominal capacity production, and mine close. In addition, the system includes all of the activities required to break the coal away from the seam, transport it to the surface, and prepare it for shipment to the customer.

4.5.3.2 Commercially Attractive. Some development is undertaken primarily to (1) demonstrate that a technically feasible solution exists to a previously 
posed research or development problem, or (2) explore possible solutions to such problems. This production cost requirement is not meant to apply to such exploratory research or proof-of-concept experiments, but rather to projects whose technology is developed to the point where it is meaningful to contemplate design, fabrication, and test of a system expected to be ready for commercial use, more or less in the form originally conceived. As indicated in the statement of the systems requirement, the degree of commercial attractiveness will be judged against an ROI criterion.

4.5.3.3 Specified Resource. Any evaluation of a candidate system must consider the range of mining conditions characteristic of the resource for. which the system is designed. These conditions typically include such factors as seam geometry (thickness, dip, and access); roof and floor quality (including any factors such as water, joints, residual stress which could affect bearing properties of the ground); methane liberation rate (which may vary with the cutting technology); and various anomalies (faults, folds, partings, pinch outs, undulations in roof and floor, etc.). To permit a determination of commercial attractiveness one must define the range of conditions in which the system may be used and specify a set of nominal conditions judged to be representative of average conditions likely to be encountered. To the extent possible, the system designer is urged to describe how production, equipment, manning, and consumables are expected to vary over the range of conditions for which the system is designed.

4.5.3.4 Show Promise. As indicated in the introductory discussion, risk is the central issue in any calculation of commercial attractiveness. For purposes of demonstrating commercial promise, one should assume that all problems of technical feasibility, and manufacturability will be solved for an R\&D expenditure typical of a development project of the type and magnitude proposed. Thus, amortization of R\&D expense per system sold should be in line with current and past industry experience, and should be considered in all projections of equipment cost. Moreover, the assumptions used to determine overall production cost, or cost savings should reflect conservative assumptions about initial construction and development expenditures, equipment cost, manning, consumables, and time actually available for production (in view of specified mining conditions, and cycle times). By "conservative," we mean average day-in/day-out performance, when operating in average conditions, using a work force of average ability and experience, working under rules typical of the region in which the resource is located, etc. Performance projections corresponding to ideal operating rates, equipment availabilities, work rules, etc., are not appropriate for the conservative meaning accorded to the phrase "show promise."

\subsubsection{Return on Invested Capital}

Return is defined as the discounted cash flow return on the incremental investment in new equipment over the life of a representative mine. This so-called "internal rate of return" is that value of the discount rate which yields a net present value of zero, when applied to all of the incremental cash flows. In order to determine the incremental cash flows, one must identify (1) the incremental investment, and (2) the incremental change in the contribution to costs and income as a result of using the new 
equipment. These incremental flows are used to compare the life cycle cost of a representative mine equipped with the advanced system, to the life cycle cost of a mine of the same size equipped with technology specified in the moving baseline for the year 2000. The baseline technology selected for this comparison is the one deemed most suitable for the mining conditions of interest, and the mine size is chosen to be appropriate to the advanced system.

Although it is possible to design a system that is totally new from mine opening and initial development to mine close, it is also possible that the investment in new hardware will be concentrated in certain areas, such as face equipment or main haulage. To fix ideas, consider a system whose only new element is face equipment. In this case, the incremental investment is merely the difference between the expenditures on the new and the old. equipment including both initial outlays and subsequent rebuilds or replacement of components important enough to qualify as capital items.

The incremental change in contribution to fixed cost and profit is determined in a similar fashion. Let us continue with the example of changed face equipment. Given a selling price f.o.b. mine* and a section production rate, one may compute the gross revenue generated by both the new and the old section equipment. To compute a contribution to fixed costs and profit, for each complement of machines, one subtracts from the gross revenue, the operating and maintenance costs, and accounts for the tax impacts of depreciation, depletion, investment tax credit, etc. The resulting incremental cash flow generated by the new equipment is discounted until its present value just equals the present value of the incremental investment. This is the unique internal rate of return associated with the new equipment.

\subsubsection{Target Return on Investment. (ROI)}

The target return on investment is based on the after-tax return required of a relatively risk-free capacity expansion or replacement project at the time of first commercial use (presumed to be approximately the year 2000). The addition of a new section to an existing mine, or the replacement of old section equipment are good examples of relatively risk-free capacity expansion and replacement projects. Because of a presumed effective federal tax rate of 50 percent, the before-tax return is generally held to be twice the after-tax return. Economists break the after-tax return into two components: (1) the long-term real rate of return, which is highly correlated with the growth in productivity, and (2) the long-term rate of inflation. If one assumes a long-term growth in productivity of 2.5 to 3 percent and a sustained inflation rate of 8 to 9 percent, then a reasonable after-tax rate of return would be 10 to 12 percent.

The above discussion is relevant to investments with relatively little risk, in contrast to the purchase of advanced equipment, which is

*This calculation is directly dependent on the market price, perhaps twenty years in the future, which is difficult to predict with any accuracy. 
generally perceived to embody considerable risk in the early stages of commercial use, no matter what level of performance may have been indicated in field tests and demonstrations. Mansfield (1978), conducted extensive research to determine what "risk premium" innovators (early adopters) demanded for the purchase of new equipment. Table 13 presents Mansfield's results for twelve innovations which eventually saw wide use in railroading, iron and steel production, coal mining, and brewing. Mansfield's measure of relative profitability was the ratio of the payback required on the firm's typical capital project to the payback projected for the innovation. Note that for the innovations studied, this ratio varied from 1.2 to 5.0 , with 1.6 to 2.0 being the range for the three coal mining innovations. Payback has. now given way to more sophisticated measures of profitability, such as internal rate of return and net present value (corresponding to a fixed rate of return). In consequence, we have sought to transform Mansfield's profitability ratio into a ratio of rates of return. The method for making this transformation is presented in Appendix D. It is shown there that, using reasonable estimates for bounding parameters, the payback ratios for mining innovations found by Mansfield of 1.6 to 2.0 can be translated into ROI ratios of approximately 1.5 to 2.5 .

Of course, this profitability ratio or risk premium concept is strictly applicable only at the point in time when an innovation is ready for use by the industry. The systems requirement on production cost must be stated in a way that provides for the evaluation of a conceptual design, whose performance is considerably less certain than a commercially available piece of hardware. We suggest two ways around this difficulty. First, as indicated above, preliminary estimates of profitability should be based on conservative projections of production, manning, equipment cost, and consumables. Second, the preliminary screening of a concept should identify areas of performance where uncertainty implies a substantial variance in the profitability projections. It is presumed that further work on a concept would focus on resolving those uncertainties, and subsequently recomputing the return on investment.

Finally, the minimum ROI ratio was set in terms of a range of 1.5 to 2.5. This is regarded as a lower bound on the ratio. For riskier developments, one may wish to require a correspondingly higher ratio.* How to quantify risk and relate a particular judgment about risk to an ROI ratio is not at all clear, or may not be the best way to deal with the issue. As indicated above, it may be more illuminating to perform some simple experiments bearing on feasibility.

\subsubsection{Target Price}

The target price is that price presumed to exist in the marketplace at the time the new equipment is introduced. This is the price that will be employed to determine the incremental revenue generated by the new equipment.

* Hill (1979) and others indicate that this is the sort of heuristic procedure industry typically uses to handle varying degrees of risk. 
Adapted from Table 7.1, Mansfield (1968)

INNOVATION
Diesel Locomotive
Centralized Traffic Control
Car Retarders
Continuous Wide-Strip Mill
By-Product Coke Oven
Continuous Annealing
Shuttle Car
- Trackless Mobile Loader
Continuous Mining Machine
Tin Container
High-Speed Bottle Filler
Pallet-Loading Machine

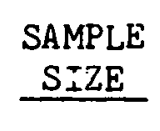

25

24

25

12

12

9

15

15

17

22

16

19
PROFITABILITY* RATIO

1.59

1.48

1.25

1.87

1.47

1.25

1.74

1.65

2.00

5.07

1.20

1.67

* The ratio reported is anticipated payback for the firm's average capital project, divided by the payback projected for the innovation.

o Coal mining innovations.

Because coal is a commodity often sold under long-term contract, it is recommended that the target price be the contract price forecast for the time period of first use. Under a contract from JPL, Energy and Environmental Analysis of Arlington, Virginia has projected long-term contract prices for the years 1985 and 2000 (see Table 14). These prices are quoted in 1980 dollars and reflect the after-tax rate of return currently realized by the industry.

\subsubsection{Method of Evaluation}

The procedure for evaluating the production cost performance of a candidate advanced mining system is a straightforward application of existing tools. The analysis begins with the description of the advanced system, as it would be employed in a mine of a size large enough to realize the inherent economies of scale. Estimated capital investment and operating costs should be assembled in a format suitable for subsequent discounted cash flow analysis. A good example of the recommended format may be found in Duda (1976). Section production, and ultimately the annual capability of a mine 
TABLE 14

TARGET PRICES FOR CENTRAL APPALACHIA

FOR THE YEARS 1985 AND 2000

Source: Energy and Environmental Analysis (1980)

\begin{tabular}{|c|c|c|c|c|}
\hline \multirow[b]{3}{*}{$\begin{array}{l}\text { COAL TYPE } \\
\text { Compliance Coal } \\
\text { (1.2\% Sulfur) }\end{array}$} & \multicolumn{2}{|c|}{1985} & \multicolumn{2}{|c|}{2000} \\
\hline & PRICE & $\begin{array}{c}\text { ANNUAL } \\
\text { PRODUCTION }\end{array}$ & PRICE & $\begin{array}{c}\text { ANNUAL } \\
\text { PRODUCTION }\end{array}$ \\
\hline & $\$ 2 \frac{(\$ / \text { TON })}{90-31.50}$ & $\frac{\text { MILLION TONS }}{128}$ & $\frac{(\$ / \text { TON })}{\$ 33.00}$ & $\frac{\text { MILLION TONS }}{174}$ \\
\hline $\begin{array}{l}\text { Low Sulfur Coal } \\
(1.2-2.0 \% \text { Sulfur })\end{array}$ & $\$ 28.00-28.50$ & 93 & $\$ 33.00$ & 180 \\
\hline $\begin{array}{l}\text { High Sulfur Coal } \\
(2.0 \% \text { Sulfur })\end{array}$ & $\$ 28.00-29.00$ & 26 & $\$ 31.00$ & 46 \\
\hline Total Production & & 247 & & 400 \\
\hline
\end{tabular}

may be determined from the sort of equipment cycle analysis employed by Floyd (1977) and Bickerton (1980).

Next, a baseline system for the resource in question should be selected, and both cost and production performance should be projected to the year when the advanced system is expected to be commercially available. Bickerton (1980) has projected year 2000 performance for room and pillar, longwall, and shortwall technology. (To ensure a close comparison, the baseline technology should be analyzed while operating at the same site as the one selected for the advanced system.) Clearly, the information describing the baseline technology should be put in the same format as the one used for the candidate advanced system.

Revenues from each mine must be projected by using the market prices presumed to hold at the time the candidate system is introduced. An overview of prices expected in Central Appalachia for period 1985-2000 has been given. A more extensive discussion of price projections for all major regional resources may be found in Terasawa (1980).

Once the cash flow profiles have been assembled for the candidate and baseline systems, it is a simple matter to obtain a schedule of the cash flow difference, year by year. This schedule of incremental cash flow may then be 
analyzed using standard techniques (see Duda (1976) for example) to determine the internal rate of return.

Next, this rate of return must be compared with that rate which industry is expected to require at the time the candidate advanced system will be commercially available. As indicated above, the comparison rate is related to productivity gains and the expected rate of inflation.

Finally, a sensitivity analysis should be conducted on those parameters which are relatively uncertain, for example, market price, mine size, and the projected cost and cycle times for the new equipment. A computer program to automate the above procedure is currently under development at JPL. 


\section{SECTION 5}

\section{SUMMARY}

This section summarizes the operating environment and desired performance of an advanced underground mining system suitable for Central Appalachia coals. Following this summary is a brief discussion of the next steps involved in translating these top-level requirements into a more detailed system definition, intended to facilitate conceptual design of hardware.

An advanced underground coal mining system for use in Central Appalachia will operate in flat lying seams of moderate thickness (30-80 inches) and encounter overburdens of less than 1,000 feet. The bulk of the resource is accessible via outcrop, and a substantial fraction of the tonnage appears to lie within a few hundred feet of the outcrop. Roof conditions range from easily caved to very difficult to cave, coupled with varying degrees of stability of the rock layer immediately above the coal seam. In many cases the spacing between seams is frequently so close that mining one seam risks permanent damage to neighboring coals above and below. Finally, a new system should be designed to operate in mines with an annual output of about 50,000 to 250,000 tons per year, with application to much larger mines desirable.

The advanced mining system will be expected to yield resource recovery ratios at least equal to those obtained by moving baseline systems. Prohibitions against subsidence presently are obstacles to increased recovery. In addition, the system must comply with environmental regulations. The production cost advantage of a system will be enhanced if less environmental impact mitigation is necessary. Minimization of refuse piles, reduction of exposure to air of acid-producing minerals, and techniques for avoiding landscape alteration will be useful in this regard.

Dust has been identified as the prime contributor to health problems of coal miners. An advanced system must comply with dust control regulations. One which intrinsically generates less dust will reduce expenditures for dust control, thus gaining economic advantage. In addition, the use of mutagenic substances in the mining process should be avoided, because it may be difficult or impossible to assure the necessary low levels of exposure.

Trends in mine safety indicate that overall accident rates for miners may soon approximate those for other workers in comparable industries. However, the fraction of serious (disabling or fatal) injuries should be reduced by a factor of two if the advanced mining system is to make mining comparable to the experience of other industries with comparable hazards. The system might work toward this goal either by creating an intrinsically safer workplace, by removing personnel from dangerous areas, or by making accident avoidance less dependent on the skill and alertness of individual miners. 
Although many factors affect the commercial attractiveness of a new mining system, the major considerations can be summarized in one measure: return on invested capital (ROI). Because any new technology embodies substantial risk, the industry typically requires a risk premium which, for coal mining, áppears to be from 1.5 to 2.5 times the return required on the typical capital replacement or capacity expansion project: The ROI improvement projected for the new equipment is based on the incremental cash flow obtained via a life cycle cost comparison with the appropriate baseline technology. In twenty years it is expected that the productivity of the baseline technology will approximately double.

The systems requirements summarized above are intentionally stated as challenging performance goals with very little guidance being given on what to change in the system in order to achieve these goals. Thus, the next step in development of advanced hardware is a more precise description of those aspects of system structure which afford the greatest opportunities for improved performance. For want of a better term, such a statement of where to focus the design effort is called the "system definition," and will be the subject of continued investigation in the Advanced Coal Extraction Systems program. 
APPENDIX A

THE RELATIONSHIP OF RECOVERY RATIO TO MINING CONDITIONS

$A-1$ 
Mining Conditions will inevitably have an important impact on coal recovery, whatever the technological solutions to ground control, coal winning, haulage, etc. Accordingly, the conservation requirement defines recovery targets as a function of conditions. The data presented in Table A-1 of this appendix represent a judgmental assessment of the relative attractiveness of the four comtemporary mining methods when faced with a variation in one geological factor (e.g. dip, floor quality, seam thickness, etc:) with all other factors held constant. These judgments were based, in part, upon assessments of the various methods made by Stefanko (1977), Kuti (1975), and Cominec (1975). The information thus obtained on individual conditions was examined to identify these factors which discriminated best among the technologies. As indicated in Section 4.1 of the text, they were:

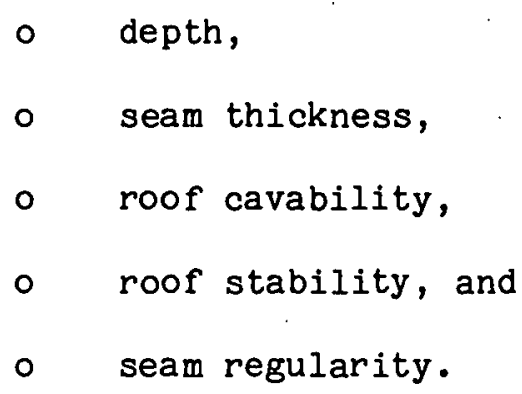

A dichotomization of each factor into high and low values produced unique sets of conditions, for which a preferred technology was nominated. Figure 6, in Section 4.1 of the text, presents the results of this analysis, which when combined with the recovery percentages of Table 8, establishes recovery minimums for each set of conditions to be expected in the target resource. 
RELATIVE ATTRACTIVENESS OF VARIOUS MINING

METHODS AS A FUNCTION OF GEOLOGICAL CONDITIONS

(Rated as 1 for most attractive to 6 for least attractive)

\begin{tabular}{|c|c|c|c|c|c|c|c|}
\hline & \multicolumn{4}{|c|}{ ROOM \& PILLAR METHODS } & \multicolumn{3}{|c|}{ CAVING METHODS } \\
\hline & \multicolumn{2}{|c|}{ CONTINUOUS } & \multicolumn{2}{|c|}{ CONVENTIONAL } & \multirow[t]{2}{*}{ LONGWALL } & \multicolumn{2}{|c|}{ SHORTWALL } \\
\hline & Pillars & No Rob & Pillars & No Rob & & Shuttle & $\underline{\mathrm{AFC}}$ \\
\hline Thick Seam & 5 & 3 & 4 & 2 & 1 & 3 & 3 \\
\hline Depth $100^{\prime}-500^{\prime}$ & 2 & 1 & 2 & 1 & 4 & 3 & 3 \\
\hline $500^{\prime}-1,000^{\prime}$ & 2 & 1 & 3 & 2 & 2 & 2 & 2 \\
\hline $1,000^{\circ}-1,500^{\prime}$ & 3 & 2 & 4 & 3 & 1 & 2 & 2 \\
\hline $1,500^{\prime}-2,000^{\prime}$ & 4 & 3 & 4 & 3 & 1 & 2 & 2 \\
\hline Weak Immed. Roof & 5 & 4 & 5 & 4 & 1 & 6 & 5 \\
\hline Strong Immed. Roof & 2 & 1 & 2 & 1 & 6 & 5 & 5 \\
\hline Weak Prin. Roof & 5 & 4 & 5 & 4 & 1 & 2 & 2 \\
\hline Strong Prin. Roof & 1 & 2 & 1 & 2 & 6 & 5 & 5 \\
\hline Weak Floor & 4 & 3 & 4 & 2 & 6 & 6 & 5 \\
\hline So-So Floor & 2 & 1 & 2 & 1 & 2 & 2 & 1 \\
\hline Strong Floor & 1 & 1. & 1 & 1 & 1 & 1 & 1 \\
\hline Surplus Water & 5 & 4 & 5 & 4 & 3 & 5 & 3 \\
\hline Faults-Frequent & 3 & 2 & 2 & 1 & 6 & 4 & 5 \\
\hline Wants, Washouts & 3 & 2 & 2 & 1 & 6 & 4 & 5 \\
\hline Partings & 2 & 1 & 2 & 1 & 2 & 2 & 2 \\
\hline Rolls & 3 & 2 & 3 & 1 & 5 & 4 & 4 \\
\hline Pitch & 1 & 1 & 1 & 1 & 2 & 1 & 1 \\
\hline $5^{\circ}$ & 2 & 2 & 2 & 1 & 4 & 3 & 3 \\
\hline Methane-Strong & 6 & 4 & 5 & 3 & 2 & 3 & 3 \\
\hline Inclusi ons-Ma jor & 3 & 3 & 1 & 1 & 2 & 2 & 2 \\
\hline Hard Cutting & 3 & 3 & 1 & $i$ & 2 & 3. & 3 \\
\hline
\end{tabular}


THIS PAGE

\section{WAS INTENTIONALLY LEFT BLANK}


APPENDIX B

COAL MINER SURVIVABILITY

B-1 
Figure B-1 compares the survivability of a hypothetical cohort of 100,000 coal miners to the survivability of an identical number of average American males. The data used to construct Figure B-1 came from Section IV of Rockette (1977). These data indicate about a 3 percent higher mortality for coal miners than for the surviving portion of the average male cohort. Rockette (1972) and others imply that a comparison like the one of Figure B-1 may understate the impact of coal miners' occupational diseases because these workers are drawn from a sub-population which may well be more robust than the aggregate American male population. A more accurate analysis would have compared coal miners' survivability with the survivability of a control population, comparable to the miners in all respects (e.g., hereditary diseases, lifestyle, diet, propensity to smoking, participation in strenuous avocations, exposure to environmental pollution, etc.). In theory, such a comparison is straightforward. However, defining a comparable population and obtaining survivability statistics is a research project beyond the scope of the work reported in this document. 


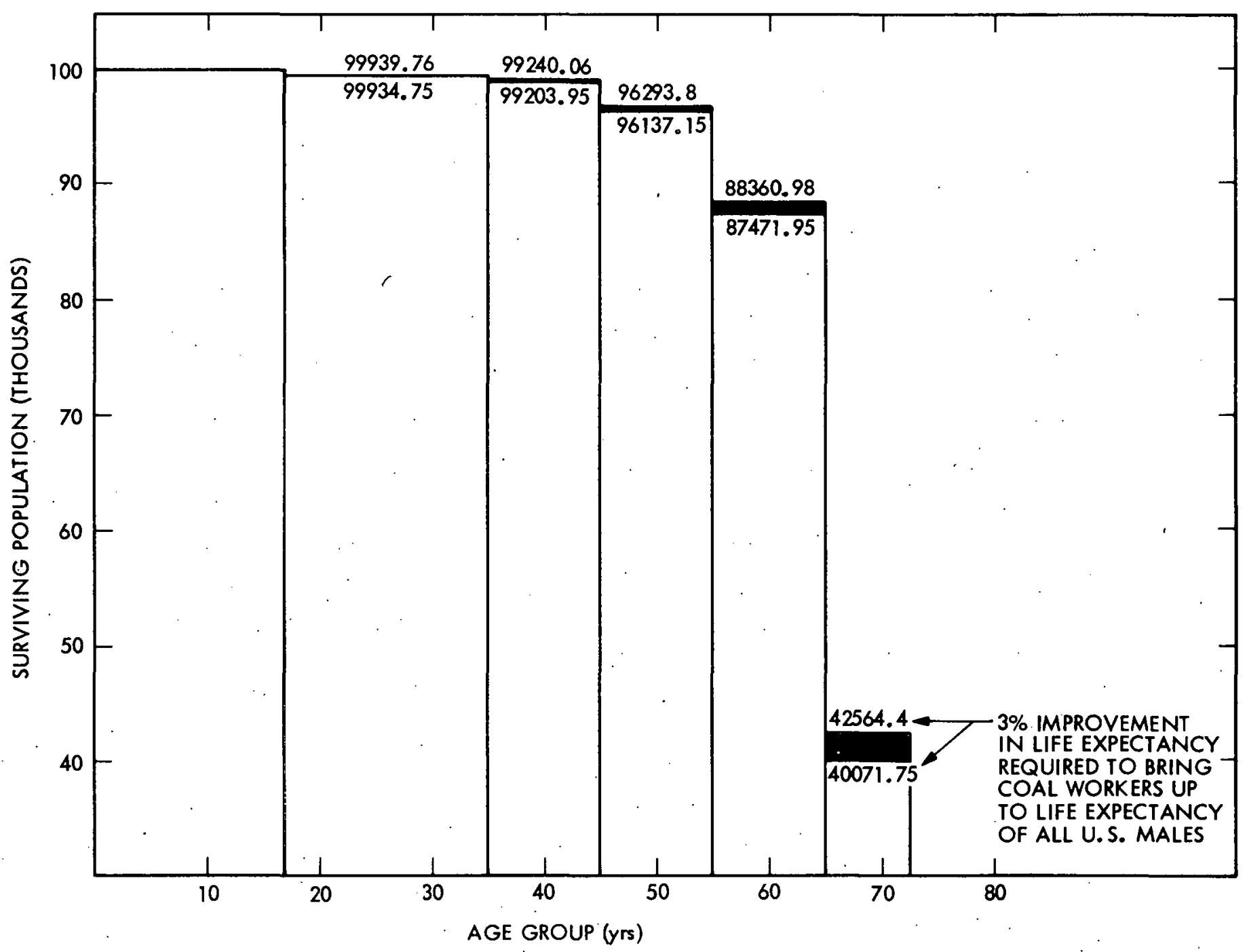

Figure B.1-1. The Life Expectancy of Coal Miners Compared with All U.S. Males, as a Function of Age 


\section{APPENDIX C}

DETAILED INFORMATION RELEVANT TO THE SAFETY REQUIREMENT

C.1 Injury Rates for Coal Mining and Comparable Industries

C.2 The Cost of Safety in Relation to the Overall Cost of Coal 


\section{THIS PAGE}

\section{WAS INTENTIONALLY \\ LEFT BLANK}




\section{APPENDIX C.I}

INJURY RATES FOR COAL MINING AND COMPARABLE INDUSTRIES 
Figùres $C .1-1$ and $C .1-2$ portray, respectively, the injury experience of underground coal mining and historical injury rates for industries judged to have comparable hazards. Note that the trend for coal mining is sharply downward, having decreased to a total injury rate of less than 70 per million man-hours in 1978, from over 120 per million man-hours in 1972. It is not surprising that the West Virginia statistics closely parallel the industry aggregate since West Virginia accounts for a large portion of total U.S. underground production. In contrast to underground coal mining, injury rates in metal mining, and petroleum production have'been rising somewhat, while the rates for primary metal manufacturing, construction, and non-metal mining (except coal) exhibit a modest decline.

These data have two implications for setting a safety requirement for underground coal mining. First, in terms of total injuries, coal mining at a rate of about 70 per million man-hours in 1978 falls near the upper portion of the range of 85 to 25 per million man-hours for comparable industries. Thus, some improvement in the total injury rate is indicated for coal mining, but it need not be regarded as a current pressing problem. However, as pointed out in the discussion of Section 5.4 of the text, rates for fatalities and disabling injuries remain very high for coal mining relative to the above set of comparable industries.

Second, it is reasonable to expect long term changes in injury rates, both for coal mining and the industries with which it is compared. Thus, the safety requirement must incorporate the notion of a moving baseline whose- role in setting safety goals is very similar to the role of the moving technological baseline in setting production cost goals. 


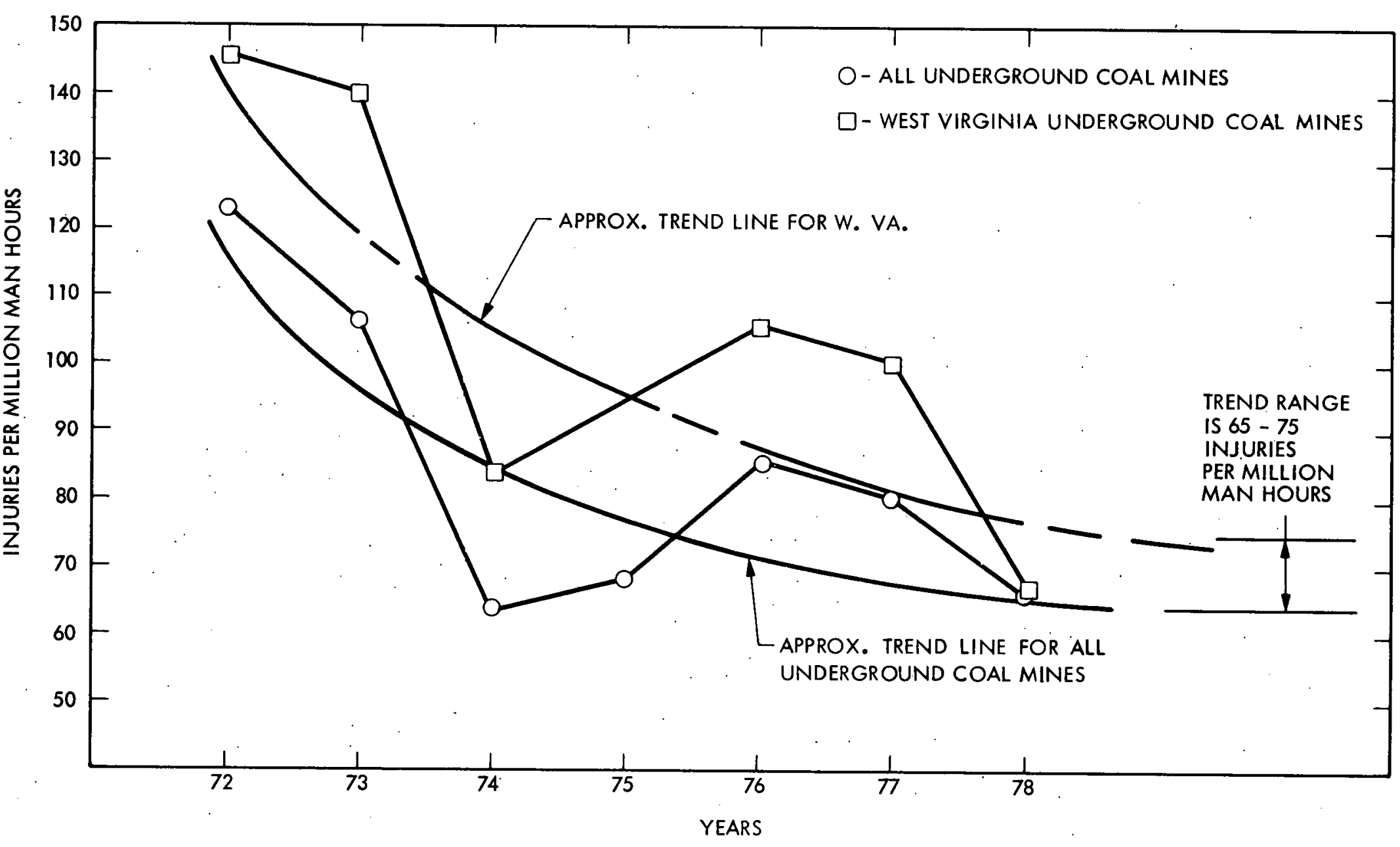

Figure C.1-1. History of Total Injuries per Million Man Hours for Underground Coal Mining with West Virginia Reported Separately 


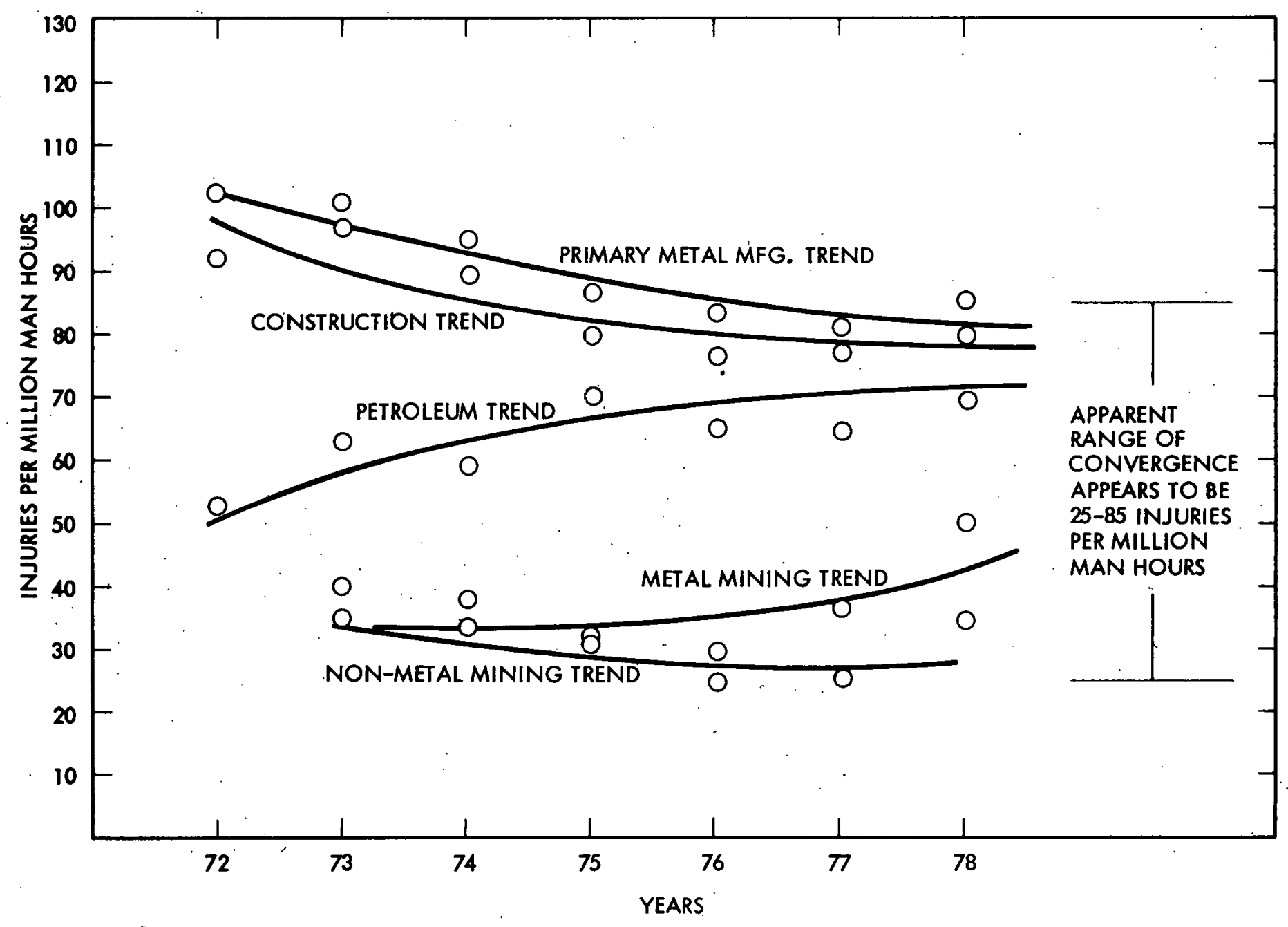

Figure C.1-2. History of Total Injuries per Million Man Hours for Industries Comparable to Underground Coal Mining 
APPENDIX C. 2

THE COST OF SAFETY IN RELATION

TO THE OVERALL COST OF COAL

C-7 
In estimating to what extent safety impacts the cost of coal, the following steps were taken: first, understand the variables affecting the value of a fatality or disabling injury; second, talk with labor, management, and government personnel to establish what changes have taken place over the years in compensating for loss of life and limb; and third, determine whether or not it is practical to place a value on fatalities and disabling injuries based on all the information previously assembled.

Research on the "value of a human life" has employed two major approaches, (1) the human capital notion, and (2) the willingness to pay concept. The human capital approach states that the value of a life is basically what a person's net worth would be, based on his earnings. This is the approach preferred by industry because it is easily quantifiable, and it is the cheapest. The willingness to pay concept essentially looks at what a person would be willing to pay to improve his chances of surviving, or not being disabled. The main difference between these two philosophies is that the human capital approach looks at a person's worth in relation to the GNP (separate from the person), and the willingness to pay approach tries to consider the person's measure of own worth (separate from the GNP). If these two philosophies could somehow be reconciled, then perhaps a practical, socially acceptable value could be reached.

However, each approach has its shortcomings. The human capital approach does not account for the value of home production, the value of leisure, upward mobility, the ripple effects within the family structure (e.g., offspring altering long-range educational goals, and subsequent higher wages, to deal with the immediacy of compensation for lost wages and family unity), and changes in mortality and injury rates. Schelling (1967) states "there is no reason to suppose that a man's future earnings, discounted in any pertinent 
fashion, bear any particular relation to what he would pay to reduce the likelihood of his own death". In view of the above discussion, McGuire (1979) observes that the legitimacy of the use of the human capital approach revolves around it being used "only as a quantification of costs that are directly or indirectly quantifiable.- not as a tool for evaluating programs that potentially prevent injury or save lives". Accordingly, many feel that the human capital approach yields a lower bound for the value of human life.

An Example of the Human Capital Approach

This conclusion is indirectly supported by Dicanio, et al.'s (1976) study of costs to industry and society from work-related injuries and deaths in underground coal mines. The model used by Dicanio, et al. is based on the human capital approach. The cost factors considered by this model include:

- Compensation payments by companies,

- Lost coal production by companies,

- Investigative costs of companies,

- Wage losses to miner and family,

- Compensation payments by public agencies, and

- Investigative costs of public agencies.

Dicanio, et al. recognize other cost variables as well, and these will be discussed later. However, this model ignores a number of other factors because they are difficult to quantify:

- Lawsuits for deaths and disabling injuries;

- The ripple effect of losses in production in all sections of a mine resulting from a fatality or major disabling injury;

- The cost of retraining and rehabilitating disabled workers;

- Long-term medical treatment expenses (i.e., usually only the immediate short-term expense required to repair the disability is considered). 
In commenting on long-term medical expenses, Dicanio et al. state that "long-term medical costs can be several times that of the short-term costs". One may argue that public and corporate compensation cover most of the above variables. However, Kerr (1979) notes that compensation benefits have not changed much within the last decade (excluding black lung, where legislation has improved benefits). The Department of Labor has been actively seeking an adjustment in public agency compensation to keep up with inflation, with only modest success. Corporate compensation programs are perhaps even less likely to keep abreast of inflation. Dicanio et al. report recent industry-wide averages for the costs of fatalities and disabling injuries as follows:

- Fatalities - \$125,000/injury

- Disabling injuries - \$4,000/injury

\section{Willingness to Pay Approach}

The "willingness to pay" concept supposedly reflects a more personal measure of worth. The problem comes in assessing the value of increasing safety for an individual. Schelling (1967) recommends questionnaires. However, a questionnaire seems to be an inadequate tool to measure this complex, emotionally charged issue. Thaler and Rosen (1973) attempted to infer what people require as compensation for risk by analyzing acceptable wage rates for various jobs. This technique yielded a value for life of approximately $\$ 200,000$. Critics of this approach point out that people who are generally insensitive to risk enter hazardous jobs. Therefore, it is felt that Thaler and Rosen's figures underestimate the true value, or willingness to pay, of the population at large. However, given that "willingness to pay" more accurately addresses the true value of life, Thaler and Rosen's result of $\$ 200,000$ may be taken as a low estimate for the value of life. This value of life will be used in an initial attempt to quantify the trade-off between production cost and safety. 


\section{Analysis of Cost-Safety Trade-off}

Consider a general cost expression which describes the total cost as a function of fatalities, permanently disabling injuries, and non-permanently disabling injuries.

$$
C_{\text {TOT }}=\left(I_{\text {TOT }} / P\right)\left(f C_{f}+d C_{d}+n C_{n}\right)
$$

Where:

$$
\begin{aligned}
& \mathrm{C}_{\mathrm{TOT}}=\text { Total cost of injuries ( } \$ / \text { ton) } \\
& \mathrm{P}=\text { Production (tons/man-hour) } \\
& I_{\text {TOT }}=\text { Total injury rate } / 10^{6} \text { man-hours } \\
& f=\text { Proportion of fatalities in relation to the } \\
& \text { total injuries } \\
& C_{f}=\text { Assumed cost of a fatality (\$) } \\
& d \quad=\text { Proportion of permanently disabling injuries } \\
& \text { in relation to the total injuries } \\
& C_{d}=\text { Assumed cost of a permanently disabling } \\
& \text { injury (\$) } \\
& \mathrm{n}=\text { Proportion of non-permanently disabling } \\
& \text { injuries in relation to the total injuries } \\
& C_{n}=\text { Assumed cost of a non-permanently disabling } \\
& \text { injury (\$) }
\end{aligned}
$$

Using the data provided in the requirements, one may make the following estimates:

$$
\begin{aligned}
& \mathrm{f}=.005 \\
& \mathrm{~d}=.03 \\
& \mathrm{n}=.58
\end{aligned}
$$

The value for a disabling injury may be estimated by assuming that it bears the same relationship to the cost of a fatality as the ratio implied by the data reported by Dicanio, et al. above, i.e.:

$$
C_{d}=200,000,(4,000 / 125,000)=6,400
$$


Moreover, to be conservative, assume that:

Now for Central Appalachia,

$$
I \quad=105 \text { injuries } / 10^{6} \text { man-hours }
$$

and

$$
P=" 1 \text { ton/man-hour }
$$

Upon substituting the above numerical values into Equation (1), one obtains a lower estimate for the cost of injuries:

$$
\begin{aligned}
C_{\text {TOT }} & =\frac{105}{(1)\left(10^{6}\right)}\left(.005\left(.2 \times 10^{6}\right)+.61\left(.0064 \times 10^{6}\right)\right) \\
& =\$ 0.52 / \text { ton }
\end{aligned}
$$

This value is less than $2 \%$ of the current long-term contract price for steam coal.

Now let us repeat the above calculations using more liberal figures for the cost of the three types of injuries:

$$
\begin{aligned}
& c_{f}=\$ 10^{6} \\
& c_{d}=\$ 10^{5} \\
& c_{n}=\$ 10^{4}
\end{aligned}
$$

Then,

$$
\begin{aligned}
C_{\text {TOT }} & =\frac{105}{(1)\left(10^{6}\right)}\left(.005\left(10^{6}\right)+.03\left(.1 \times 10^{6}\right)+.58\left(.01 \times 10^{6}\right)\right) \\
& =\$ 1.47 / \text { ton }
\end{aligned}
$$

It appears that even with more liberal assumptions about the value of life and limb, the cost of injuries is a small percentage of the cost of coal. This is not to be construed as saying that safety is not important. Rather, it says that the value placed on safety may outweigh pro forma cost calculations. In sum, there is no justification for any serious attempt to make trade-offs between safety and production cost. 
DETAILED INFORMATION RELEVANT TO

THE PRODUCTION COST REQUIREMENTS

D.1 The Relationship Between Return on Investment and Payback.

D.2 Opportunities for Meeting the Production Cost Requirement 


\author{
THIS PAGE \\ WAS INTENTIONALLY \\ LEFT BLANK
}

D-2 
In the work by Mansfield (1968), ROI was not directly measured, nor did the researchers attempt to translate the reported payback ratios into ROI terms. The relationship between the two profitability measures is the subject of this appendix.

Consider a piece of equipment which costs $P$, lasts $n$ years, and generates $r$ dollars of net cash flow each year. Assume that the equipment is renewed continually, resulting in an infinite sequence of investments and cash flows. Let $i$ be the internal rate of return (ROI) generated by the investment. It is easy to show that the Present Value (PV) of the infinite sequence of investments is

$$
P V(\text { investment })=P /\left(1-e^{-i n}\right)
$$

under the assumption of continuous compounding. Similarly, the expresion for the Present Value of the cash flow generated is

$$
\mathrm{PV}(\operatorname{cash} \mathrm{flow})=\int_{0}^{\infty} r e^{-i t} d t=r / i
$$

which is a well known result from engineering economy. The internal rate of return is determined by equating the two present value expressions:

$$
\mathrm{PV} \text { (investment) }=\mathrm{PV} \text { (cash flow) }
$$

whence

$$
\begin{gathered}
P /\left(1-e^{-i n}\right)=r / i \\
\text { or } \quad(P / r)=m=\left(1-e^{-i n}\right) / i
\end{gathered}
$$


which is the explicit relationship between the payback period $m$ and the internal rate of return $i$.

In the cost requirements definition, we used data on a ratio of payback periods. To interpret the result of Equ. 3 in terms of this ratio, let us denote the average capital project with a zero subscript (o) and the innovation with a unity subscript (1). Then, formally, the ratio of payback periods may be expressed as:

$$
\frac{m_{0}}{m_{1}} \quad \bar{i}_{1} \frac{1-e^{-i_{0} n_{0}}}{1-e^{-i_{1} n_{1}}}
$$

The problem is to find the return on investment which is required to justify the innovation, given a constraint on the minimum payback ratio. Note that $\mathrm{m}_{0} / \mathrm{m}_{1}, \dot{i}_{0}$, and $\mathrm{n}_{1}$ are all known quantities. Using this information, we define a new variable $K$ which permits Equ. (4) to be put into a form suitable for numerical solution:

$$
i_{1}+K e^{-i_{1} n_{1}}-k=0
$$

where:

$$
K=\frac{m_{0}}{m_{1}} \frac{1_{0}}{\left(1-e^{-i_{0} n_{0}}\right)}
$$

Equ. (5) is readily solved by Newton's method. The initial estimate for $i_{1}$, given below insures rapid convergence to a solution:

$$
i_{1}^{(0)}=\frac{\left(e^{K n_{1}}-K n_{1}-1\right)}{\left(e^{K n_{1}} / K\right)-n_{1}}
$$


Table D.1-1 presents the results of a parameter study of Equ.(4), which spans a broad range of values for $n_{0}, n_{1}$, $i_{0}$, and $i_{1}$. Analysis of the tabulated values indicates that bracketing cases contain the following sets of values:

$$
\begin{aligned}
& \text { low minimum ROI: } \mathrm{n}_{0}=10, \mathrm{n}_{1}=5, \mathrm{~m}_{0} / \mathrm{m}_{1}=1.6 \\
& \text { high minimum ROI: } \mathrm{n}_{0}=5, \mathrm{n}_{1}=10, \mathrm{~m}_{0} / \mathrm{m}_{1}=2.0
\end{aligned}
$$

The relationship between minimum ROI and payback ratio is plotted in Figure D.1-1 for these two cases, with the cross hatched area representing the region in which innovations are expected to fall. Examination of the cross hatched region reveals that an ROI range of 1.5 to 2.5 corresponds well to a payback range of 1.6 to 2.0 , in view of the probable variability in Mansfield's (1968) data, and the need to require a minimal risk premium.

3 
TABLE D. $1-1$

MINIMUM REQUIRED ROI FOR AN INNOVATION ( $i_{1}$ ) AS A FUNCTION OF PAYBACK RATIO $\left(\mathrm{m}_{0} / \mathrm{m}_{1}\right)$, PROJECT LIFETIMES $\left(n_{0}, n_{1}\right)$ AND ROI FOR AN AVERAGE CAPITAL PROJECT

\begin{tabular}{|c|c|c|c|c|c|c|c|c|c|}
\hline $\mathrm{m}_{0} / \mathrm{m}_{1}$ & \multicolumn{5}{|c|}{1.6} & \multicolumn{4}{|c|}{2.0} \\
\hline${ }^{n_{0}}$ & & 5 & 10 & 10 & 5. & 5 & 10 & 10 & 5 \\
\hline $\mathrm{n}_{1}$ & & 5 & 10 & 5 & 10 & 5 & 10 & 5 & 10 \\
\hline \multirow[t]{9}{*}{$i_{0}$} & .08 & .311 & .203 & . 118 & . 380 & .431 & .272 & .188 & .481 \\
\hline & .10 & .334 & .228 & .142 & .399 & .458 & .301 & .220 & .505 \\
\hline & .12 & .358 & .253 & .168 & .419 & .486 & 331 & .254 & . 529 \\
\hline & .15 & .394 & .293 & .211 & .450 & .529 & .337 & .308 & .567 \\
\hline & .18 & .431 & .333 & .256 & .481 & .572 & $.425^{18}$ & .365 & .605 \\
\hline & .20 & .456 & .360 & .288 & .503 & .602 & .458 & .403 & .632 \\
\hline & .25 & .520 & .430 & • 370 & .559 & .677 & .542 & .50 .1 & .700 \\
\hline & $\cdot 30$ & .585 & .502 & .455 & .617 & .755 & .630 & .600 & .772 \\
\hline & .50 & .860 & .805 & .790 & .871 & 1.085 & 1.007 & 1.000 & 1.089 \\
\hline
\end{tabular}




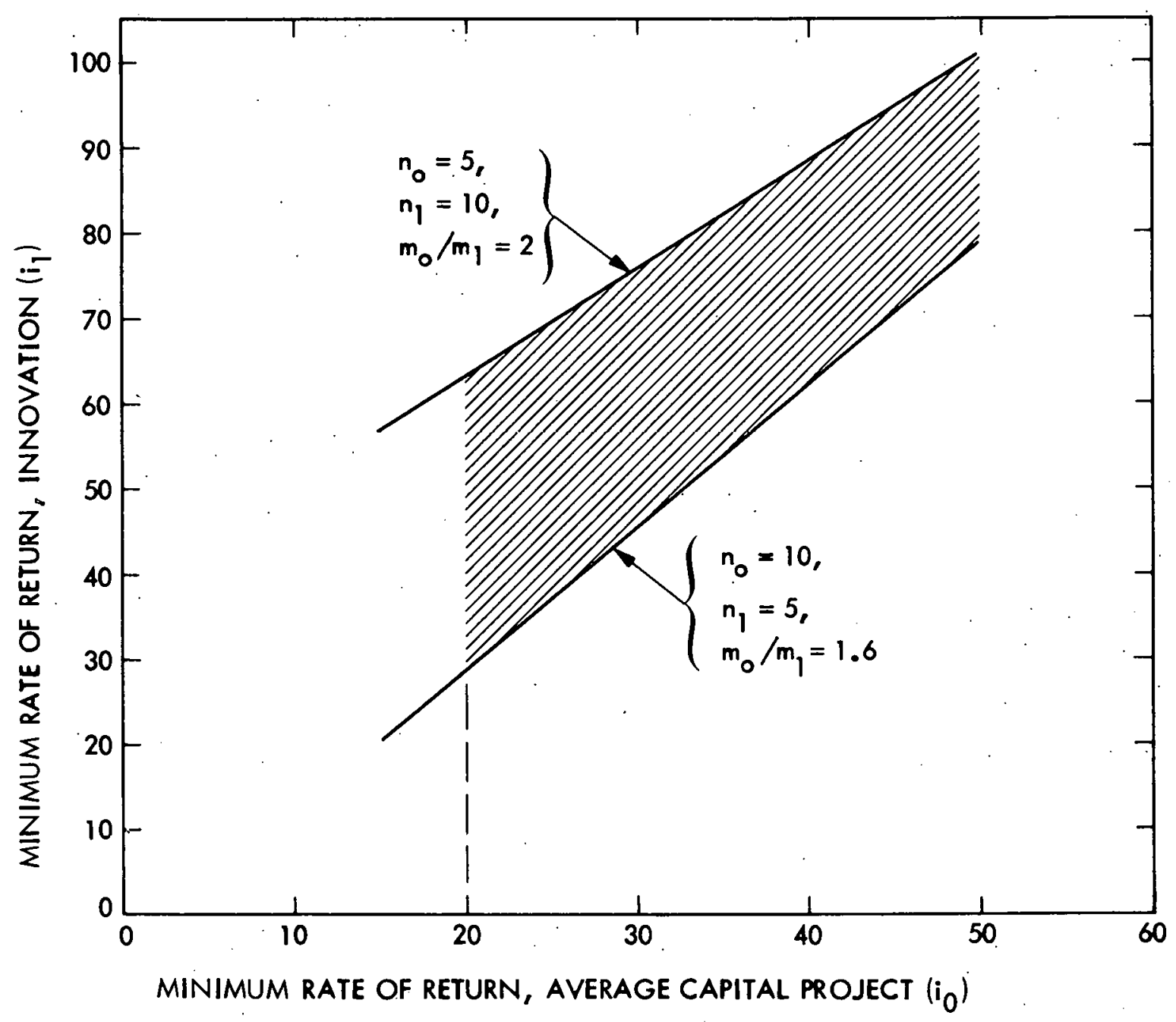

Figure D-1. Interpretation of Payback Ratio as a Ratio of Minimum Rates of Return 


\section{THIS PAGE \\ WAS INTENTIONALILY \\ LEFT BLANK}


APPENDIX D.2

OPPORTUNITIES TO MEET THE PRODUCTION COST REQUIREMENT

There is no formula for identifying opportunities for meeting the requirement posed for production cost. There are, however, a number of different approaches, all of which boil down to sensitivity analysis of some quantitative description of underground coal mining.

Lavin, et al (1978) developed an algebraic description of deep coal mining, and subsequently used this model to compute price sensitivity coefficients. Formally, a price sensitivity coefficient is defined as the percent change in price as a result of a one percent change in the variable of interest. It is rare to find a variable whose impact on price is not moderated by the effects of other factors, thus, price sensitivities tend to be substantially less than one.

The algebraic description mentioned above has two drawbacks which make it less than ideal for the present purpose. First, it is a relatively onerous task to update all of the model coefficients to reflect first quarter 1980 costs. Second, the model is structured around labor and capital productivities which are derived variables. We now feel it is more meaningful to talk about tons per section-shift (or section-hour). Consequently, we elected to use an existing computer-based model for the sensitivity work needed to identify opportunities for meeting the cost requirements.

The model used was developed by the NUS Corporation for EPRI, and subsequently made available to JPL by DOE. The price sensitivities reported in Table D.2-1 were developed for a 1.37 million ton/yr room and pillar mine, 
TABLE D.2-1. PRICE INFLUENCE COEFFICIENTS

(PERCENT CHANGE IN PRICE DUE TO PERCENT CHANGE IN FACTOR)

1.37 TON/YR ROOM AND PILLAR MINE IN YEAR 2000)

IOUS/ULCHUIVE SHIEI

0.7661

LAROR RELATED EXPENISE:

HOLRLY PERSOHIVEL $\quad 0.3050$

MELFARE RATE/MAII-HOUR $\quad 0.0350$

SALARIED PERSONIIEL

0.430

TOVïUAGE RELATED EXPEELSE:

SUPPLIES AND MATERIAL/TON $\quad 0.2475$

UHION NELFARE RATE/TOII $\quad 0.0699$

POHER COST/TON 0.0085

ROYALTY COST/TON $\quad \leq 10^{-4}$

0.3259

BRODUCTIONL SECTLOY A'D HAULAGE EMUIPUENI:

PRODUCTION SECTIOAI EQUIPMENT $\quad 0.0748$

PREPRODUCTION HAULAGE $\quad 0.0225$

PRODUCTION HAULAGE .

0.1113

ELIAPUICIAL FACTORS:

INTEREST RATE ON BORROWED CAPITAL 0.1259

PORTIOHI OF CAPITAL BORROHED $\quad-0.0657$

RATE OF RETURN DESIRED

0.1082

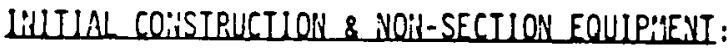

OTHER SURFACE CONSTRUCTION

0.0511

HEAVY EQUIPHENT

0.0195

PRODUCTION SITE AID VENT. CONSTR.

0.0158

PREPRODUCTION SITE PREPARATION

0.0049

VENTILATIOH EJUIPMENT

0.0030

EXPLOPATION

0.0006

SHAFTS, MIINE ENTRIES, ABANDONMENT

$\leq 10^{-4}$

0.0949

IWUTAL DEVELRPHENI EXPEHSE:

DIRECT AND IHDIRECT DEV, COST $\quad 0.0438$

DEVELOPAENT TIME

$0.0018 \quad 0.0456$

IAXES:

FEDERAL TAX RATE $\quad 0.0389$

STATE TAX RATE 0.0019

0.0408

SEAM RECOVERY EACTOR

$-0.0140$

OIHER EXPEIISE:

COPYUNICATIONS EOUIPNENT $\quad 0.0018$

FIRE AIID SAFETY EOUIPMENT $\quad 0.0012$

DEWATERING SYSTEM $\quad 0.0012$

MISCELLANEOUS ITEMS

$$
\text { D-10 }
$$

0.0024

0.0066 
operating in a five-foot seam in Central Appalachia in the year 2000. These sensitivities were derived by making successive one variable changes, with all other variables held constant. In each case the variable of interest was increased or decreased by 20\%. Thus, the tabulated values approximate the results of rather substantial changes in either response inputs or coal output.

Note that the sensitivities are listed in decreasing order of importance, with section output being far and away the most important, at a value of 0.77 . In order of decreasing importance we find hourly labor costs at 0.31 , operating supplies and other consumables at 0.25 , and the cost of production section equipment at 0.07 .

These figures, which are in general agreement with the algebraic results of Lavin, et al, (1978) have fairly clear implications for the overall architecture of a system with substantially improved cost performance. A certain amount of improvement can be realized by reducing manning costs (and. possibly the cost of operating supplies) if the corresponding increase in the cost of underground equipment is kept within bounds. However, a much more attractive strategy is to develop face equipment which is much more productive together with any required upgrading of fixed haulage. To oversimplify it a bit, one can either (1) reduce the resource inputs, or (2) expand the coal output. Expansion of output is more appealing even when one recognized that this expansion will be achieved at some cost. Note that the sensitivity to the cost of section equipment is an order of magnitude less than the sensitivity to increased shift output. 
REFERENCES

Arthur D. Little, Inc., Conceptual Design of a Fully Automated Continuous Mining System Operating Under Remote Supervisory Control, Final Report, U.S. Bureau of Mines, Contract No. J0166007 (December 1977).

Averitt, P., "Coal Resources of the United States of 1974", Bulletin 1412, United States Bureau of Mines (1975).

Bickerton, C. R., A Moving Baseline for the Evaluation of Advanced Coal Extraction Systems, a Jet Propulsion Laboratory report, to be published (1980).

Camilli, F. A., Description of Mining Conditions for Advanced Coal Extraction Systems Operating in Central Appalachia, a Jet Propulsion Laboratory report, to be published. (1980).

Casanova, P., MINEX, Paris, France, private communication followed by a letter (July 1979).

Coal Age, "The Yardstick of Productivity... Is It High Tons Per Man-Day or Is It Low Cost Per Ton?" and the following articles by J. J. Yaneik; M. Duel; T. Crocker and J. Corwine; H. Parkinson, D. R. Forshey, and J. N. Murphy; J. L. Habberstod and J. Corwine; W. K. Klegsteuber and T. M. Nasiatkos: E. R. Palowitch and J. Corwine; K. Strebig and H. B. Reese; D. L. Donner and E. Kruse; T. W. Martin and H. B. Reese; D. W. Wisecarver and L. W. Gibbs; M. 0. Magnuson and R. Cox; A. W. Deurbrouck. pp. 93-140 (July 1975).

COMINEC, Conceptual Design of an Automated Longwall Mining System, U.S. Bureau of Mines Final Report, Contract No. S0241051, NTIS PB-263 213, April 1976.

Davies, D., "Disability and Coal Workers Pneumoconiosis", Br. Med. J., 2:652 $(1974)$.

Dicanio, D. G., Nakata, A. G., Colvert, D., and La Veque, E. G., Accident Cost Indicator Model to Estimate Costs to Industry and Sooiety from Work Related Injuries and Deaths in Underground Coal Mining, FMC Corporation, Final Report on U.S. Bureau of Mines Contract No. J0255031, NTIS Report No. PTS 264-438 (1976).

Doyle, F. J., Blatt, H. G., and Rapp, J. R., Analysis of Pollution Control Costs, EPA Technology Series Report, EPA-670/2-74-009 (1974).

Duda, J. R. and Hemingway, E. L., "Basic Capital Investment and Operating Costs for Underground Bituminous Coal Mines. Developed by Longwall Mining", Information Circular 8715, U.S. Bureau of Mines (1976).

Dumbrack, D., Foster-Miller Associates; Inc., Waltham, Mass., private communication (May 1979).

Dutzi, E. J., Sullivan, P. J., and Hutchinson, C. F., Environmental Assessment of a Baseline Coal Mining System, a Jet Propulsion Laboratory report, to be published (1980). 
Energy and Environmental Analysis, Forecast of Long Term Coal Supply and Mining Conditions: Model Documentation and Results (March 1980).

Environmental Protection Agency, Effluent Guidelines Division, The Economic Impact of Proposed Guidelines for Coal Mining, Report No. EPA-204/1-75-0586 (1975).

Floyd, E. L., "Borehole Hydraulic Coal Mining System Analysis", Publication 77.-19, Jet Propulsion Laboratory (1977).

Frantz, R. L., Pennsylvania State University, personal communication on the subject of evaluating the riskiness of research and development in mining (December 1979).

Frantz, R. L. King, R. H., and Bartsch, D., "Report on the Second Subprogram Coordination Meeting on the Automated Remote Controlled Continuous Mining Program", unpublished report to U.S. Bureau of Mines (March 1977).

Frantz, R. L., King, R. H., and Bickerton, C. R., Analysis, Evaluation, and Selection of Candidate Continuous Mining Systems Suitable for Automated Operation Under Remote Supervisory Control: Tasks A and D Appendix, USBM Contract No. J0166007 (December 1977).

Frantz, R. L., King, R. H., and Bickerton, C. R., "First Conference on the Automated Remote Controlled Continuous Mining Program", unpublished report to U.S. Bureau of Mines (December 1975).

Fraser and Pare, Diagnosis of Diseases of the Chest, Saunders Co. (1977).

Freed, Donald, National Mine Service Company, Nashville, Illinois, private communication (November 1979).

George C. Marshall Space Flight Center, NASA, Development of Mining Guidance and Control Systems, Report No. ALW-11 (September 1977).

Gordon, P. G., A Review of Underground Mining Equipment Research, Jet Propulsion Laboratory, to be published (1980).

Gross, M. A., Department of Energy, Pittsburgh, Pennsylvania, private communication (April 1979).

Harris, J., The Conservation of Resources as a Consideration in Advanced Coal Extraction Systems Design for the Underground Coals of Central Appalachia, a Jet Propulsion Laboratory working paper (1980).

Harrold, R., "Supports Boost Output and Safety", Coal Age, (June 1979).

Heitzman, E. R., The Lung: Radiologic-Pathologic Correlations, Mosby Co. (1973).

Hertz, D. B., "Risk Analysis in Capital Investment", Harvard Business Review, pp. 169-181 (Sept-Oct 1979).

Hill, F., Emory Ayers Associates, personal communication (December 1979). 
Huddle, J. W. et al., Coal Reserves of Eastern Kentucky, Bulletin 11<0, United States Geological Survey (1963).

Jacobi, 0., Praxis der Gebirgsbeherrschung, Verlag Gluckauf Gmbh, Essen (1976).

Katen, K. P.; "Analysis of United States Shortwall Mining Practices", Mining Congress Journal (January 197y).

Kentucky Department of Mines and Minerals, Lexington, Kentucky, Annual Report (1978).

Kerr, L., Director of Health and Safety, United Mine Workers, personal communication (December 1979).

King, E. J. and Fletcher, L. M., Industrial Pulmonary Diseases, pp. 221-231 $(1960)$.

Kiskis, J., Jet Propulsion Laboratory, Pasadena, California, private communication (November 1979).

Kuti, J., "Longwall Mining in America", Mining Engineer (November 1979).

Kuti, J., "Longwall vs. Shortwall Systems", paper presented at the American Mining Congress Annual Coal Convention (May 1975).

Laird, W., Gates Engineering Company, personal communication (1979).

Lavin, M. L., Borden, C. M., and Duda, J. R., A Life Cycle Description of Underground Coal Mining, U.S. Department of Energy Report No. FE-9036/1 (1978). Lorenz, K., On Aggression, Harvest Books (1966).

Lyons, J. P., Ryder, R., Campbell, H., and Gough, J., "Pulmonary Disability in Coal Workers Pneumoconiosis", Br. Med. J., 1:713 (1972).

Mangolds, A., A Methodology for Evaluating Strata Control, a Jet Propulsion Laboratory working paper (1980).

Mansfield, E., Industrial Research and Technological Innovation, W. W. Norton Co. (1968).

Mayercheck, W., Department of Energy, Pittsburgh, Pennsylvania, private communication (April 1979).

McGuire, P. A., "Estimating the Value of Saving Life and Preventing Injury: A Survey", unpublished manuscript, Economics Group, Jet Propulsion Laboratory (1979).

Mine Safety and Health Administration, Division of Mining Information System, "Injury Experience in Coal Mining (1971 to 1979).

MHSA, Code of Federal Regulations Title 30, Mineral Resources, United States Department of Interior, (Revised July 1, 1976).

Morgan, W. K. C., "Respiratory Disease in Coal Miners", J.Am. Med. Assn., $231: 1347$ (1975). 
Nacye, R. L., Mahon; J. K., and Pellinger, W. S., "Rank of Coal and Coal Workers Pneumoconiosis", Am. Rev. Resp. Dis., 103:350 (1971).

National Coal Association, Washington, D.C., Coal Facts (1978-1979).

National Coal Board, Chainless Haulage Systems for Power Loaders, U.S. DOE Report FE/SFMP-1(78)(1978).

National Mine Service Company, Automated Extraction System, Final Report, DOE Contract No. ET-75-C-01-9011 (March 1977).

Occupational Health and Safety Administration, "Occupational Injuries and Illnesses in the United States by Industry", (1972-1978).

Olsen, J. J. and Tandanand, S., Mechanized Longwall Mining, USBM Information Circular 8740 (1977).

O'Toole, R. P. and Walton, A. L., Intergenerational Equity and Conservation, Jet Propulsion Laboratory Report No. 80-49 (1980).

Paranko, N. M., Yyshchisan, V. F., and Naumenko, B. S., "Stable Functional Disruptions in Miners Exposed to Permissible Levels of Vibration and Noise", Krivoy Rog Scientific Research Institute of Industrial Hygiene and Occupational Diseases, Russian (translation) (undated).

Parker, J., Department of Natural Resources, West Virginia, personal communication (1979).

Penman, R. W., "Conference on Pneumoconiosis: A Summary of the Conclusions from an International Conference on Coal Workers Pneumoconiosis", Am. Rev. Resp. Dis., 10之: 243 (1970).

Perelman, L. J., Intergenerational Equity and Energy Policy, Jet Propulsion Laboratory working paper (1980).

Pollard, T., "World Wide Developments in Shortwall and Wide Web Mining Techniques", The Mining Engineer, (November 1975).

Rasmussen, N. L., and Nelson, C. W., "Respiratory Function in Southern Appalachian Coal Miners", Am. Rev. Res. Dis., 102:240 (1970).

Reese, R. G., Dash, B. B. and Hamilton, P. A., Coal Recovery from Underground Bituminous Coal Mines in the United States, by Mining Method, Information Circular No. 8785, U.S. Bureau of Mines (1978).

Reynolds, R., Lands Officer, Daniel Boone National Forest, personal communication (1979).

Rockette, H., "Mortality Among Coal Miners Covered by the UNWA Health Retirement Funds", United States Department of Health, Education, and Welfare, Public Health Service-Center for Disease Control, NIOSH (March 1977).

Rybak, C., Bendix Corporation, Denver, Colorado, private communication (May 1979). 
Schelling, T. C., "The Life You Save May be Your Own", in Problems in Public Expenditure Analysis, ed. by Samuel B. Chase, Brookings Institution (1967).

Schroeder, E. W., et al, Analysis of the Economic Feasibility of the Kloswall Longwall Mining System, U.S. DOE Report HCP/T77-01-8915-01(7) (December 1978).

Stefanko, R., Professor of Mining Engineering, unpublished manuscript, Pennsylvania State University, University Park, Pennsylvania (1977).

Stefanko, R. and King, R. H., "First Report on Conference on Research and Development Needs for Innovative Mining Methods", unpublished report to U.S. Bureau of Mines (April 1975).

Stuermer, D. and Hatch, F., Lawrence Livermore Laboratories, personal communication (January 1980).

Suboleski, S., Continental Illinois Bank and Trust Co, personal communication on the subject of evaluating risky projects (December 1979).

Sullivan, P. J. et al., A Methodology for the Environmental Assessment of Advanced Coal Extraction Systems, a Jet Propulsion Laboratory report, to be published (1980).

Summers, D., Professor of Mining Engineering, University of Missouri-Rolla, private communication (July 1979).

Terasawa, K. L., and Whipple, D. R., Regional Price Targets Appropriate for Advanced Coal Extraction Systems, a Jet Propulsion Laboratory report, to be published (1980).

Thaler, R. and Rosen, S., The Value of Saving a Life: Evidence from the Labor Market, unpublished paper, Department of Economics, University of Rochester (1973).

U.S. Bureau of Mines, "Demonstrated Coal Reserve Base of the United States, Mineral Industry Survey (1977).

West Virginia Department of Mines, Charleston, 1978 Annual Report and Directory (1978).

White, G. R., and Graham, M. B. W., "How to Spot a Technological Winner", Harvard Business Review, pp. 146-152 (March-April 1978).

Zimmerman, W. F., A Safety Methodology for the Evaluation of Advanced Coal Extraction System, a Jet Propulsion Laboratory report, to be published (1980a).

Zimmerman, W. F., A Health Methodology for the Evaluation of Advanced Coal Extraction Systems, a Jet Propulsion Laboratory report, to be published $(1980 \mathrm{~b})$.

Zimmerman, W. F., Health Requirements for Advanced Coal Extraction Systems, a Jet Propulsion Laboratory report, to be published (1980c). 